\title{
Alternaria brassicicola - Brassicaceae pathosystem: insights into the infection process and resistance mechanisms under optimized artificial bio-assay
}

\author{
Marzena Nowakowska • Małgorzata Wrzesińska • Piotr Kamiński • Wojciech Szczechura • \\ Malgorzata Lichocka • Michał Tartanus • Elżbieta U. Kozik • Marcin Nowicki $\mathbb{C}$
}

Accepted: 10 July 2018 / Published online: 6 August 2018

(C) The Author(s) 2018

\begin{abstract}
Heavy losses incited yearly by Alternaria brassicicola on the vegetable Brassicaceae have prompted our search for sources of genetic resistance against the pathogen and the resultant disease, dark leaf spot. We optimized several parameters to test the performance of the plants under artificial inoculations with this pathogen, including leaf age and position, inoculum concentration, and incubation temperature. Using these optimized conditions, we screened a collection of 38 Brassicaceae cultigens with two methods (detached leaf and seedlings). Our results show that either method can be used for the A. brassicicola resistance breeding, and
\end{abstract}

Electronic supplementary material The online version of this article (https://doi.org/10.1007/s10658-018-1548-y) contains supplementary material, which is available to authorized users.

M. Nowakowska $\cdot$ M. Wrzesińska $\cdot$ P. Kamiński $(\bowtie) \cdot$

W. Szczechura • E. U. Kozik

Department of Genetics, Breeding, and Biotechnology of

Vegetable Crops, Research Institute of Horticulture, Skierniewice, Poland

e-mail: piotr.kaminski@inhort.pl

\section{Lichocka}

Laboratory of Confocal and Fluorescence Microscopy, Institute of Biochemistry and Biophysics - Polish Academy of Sciences,

Warszawa, Poland

M. Tartanus

School of Informatics, State Higher Vocational School in

Skierniewice, Skierniewice, Poland

M. Nowicki $(\bowtie)$

Department of Entomology and Plant Pathology, Institute of Agriculture, University of Tennessee, Knoxville, TN, USA e-mail: mnowicki@utk.edu that the plant genotype was crucial in determining its response to the pathogen. The bio-assays for A. brassicicola resistance were run under more stringent lab conditions than the field tests (natural epidemics), resulting in identification of two interspecific hybrids that might be used in breeding programs. Based on the results of the biochemical analyses, reactive oxygen species and red-ox enzymes interplay has been suggested to determine the outcome of the plant- $A$. brassicicola interplay. Confocal microscopy analyses of the leaf samples provided data on the pathogen mode of infection: Direct epidermal infection or stomatal attack were related to plant resistance level against $A$. brassicicola among the cultigens tested. Further, the microscopic analyses suggested rapid actin network activation of the host cells around the papillas deposited under the pathogen appressorium.

Keywords Alternaria resistance $\cdot$ Bio-assays · Dark spot disease $\cdot$ Resistance breeding $\cdot$ Resistance mechanisms

\section{Introduction}

Cabbages and edible brassicas feed humans worldwide, placing 5th in the global production as a major vegetable crop (FAOSTAT data). Dark leaf spot of brassicas -also referred to as black spot (Brazauskienè et al. 2011; Scholze and Ding 2005) or Alternaria blight (Kumar et al. 2014; Meena et al. 2004)- is caused by Alternaria fungi (A. brassisicola [Schw.] Wiltsh, A. brassicae [Berk.] Sacc., A. raphani [Groves \& Skolko], and 
A. alternata [Fr.] Kreissler (Bock et al. 2002; Köhl et al. 2010; Kubota et al. 2006; Kumar et al. 2014)). The disease is the major bottleneck in the global production of cultivated oilseed crops, Chinese cabbage, head cabbage, broccoli, cauliflower, and other important crops from the Brassicaceae family. It leads to 15 to $70 \%$ losses, mainly by infection of seeds and seedlings, but also of the edible produce (Kumar et al. 2014; Nowicki et al. 2012b; Shrestha et al. 2005). Production of the vegetable brassicas is mainly affected by $A$. brassicicola and $A$. brassicae, whereas the oleiferous seed crops are mainly affected by A. brassicae (Kumar et al. 2014; Michereff et al. 2012; Nowicki et al. 2012b). The dark leaf spot disease is particularly common in tropical or subtropical regions, but also threatens the Brassicaceae production in areas with high humidity and frequent rainfall (Humpherson-Jones and Phelps 1989). In Poland, this disease mainly impacts the mid- and lateseason cultivars of head cabbage, grown for storage or sauerkraut processing (reviewed by Nowicki et al. 2012 b). Poland ranks 5th or 6th in global production of these crops (FAOSTAT), and thus, the yearly threats of Alternaria spp. (Kasprzyk et al. 2013) causing yield losses and necessitating heavy protective fungicide usage (Nowicki et al. 2012b) are economically important issues.

Both main pathogens, A. brassicicola and A. brassicae, infect host plants at all developmental stages. Typical disease symptoms - dark brown spots/ lesions with characteristic concentric circumferences, often with a yellowish chlorotic halo - appear on leaves, stems, and siliques. Under conducive conditions, the colored spots develop a layer of brown-black conidial spores. The enlarging necrotic lesions drastically reduce the photosynthetic efficiency, hasten the plant senescence, and lead to collapse and death of plants under high pathogen pressure. Such symptoms generate several sources of Brassicaceae crops losses caused by black spot: Damping-off of seedlings, spotting of leaves of cabbages, blackleg of heads of cabbages (head cabbage and Chinese), and spotting/browning of cauliflower curds and broccoli florets (reviewed by Kumar et al. 2014; Nowicki et al. 2012b).

In order to augment the integrated pathogen control, resistant Brassicaceae crops are needed. Although significant efforts have been contributed, to date no Alternaria-resistant cultivars exist, and the resistant wild Brassicaceae plants do not cross well with the domesticated ones (Hansen and Earle 1997). For planning of the breeding programs designed to develop pathogenresistant cultivars, it is important to find sources of Alternaria resistance in the Brassica oleracea germplasm, including white head cabbage or cauliflower. A successful breeding program also relies on the methods for distinguishing the genetic differences in resistance early in the plant development.

The main goal of our study was to search for sources of A. brassicicola resistance in the Brassicaceae germplasm. To address this issue, we assessed techniques for rapid evaluation of A. brassicicola resistance in Brassica oleraceaea under controlled conditions. This study aimed to compare the detached leaf and seedlings bioassays regarding important variables such as age of leaf, leaf position, inoculum concentration, and incubation temperature. Both testing methods were also compared with the results of the field assessment of Alternaria resistance across a broad collection of germplasm. Moreover, confocal investigations were employed on the double-stained samples of inoculated leaves, to gain insights into the subcellular processes accompanying the A. brassicicola infection of plants differing in susceptibility. Analyses of several biochemical markers in the course of infection helped conclude on the resistance mechanisms in the plants of contrasting reactions to the infection.

\section{Materials and methods}

Plant and pathogen material

Brassicaceae germplasm used in this study included cultivars, breeding lines, interspecific hybrids, landraces, and wild accessions from the germplasm collection at the Research Institute of Horticulture (InHort; Skierniewice, Poland), and Institute of Natural Fibres and Medicinal Plants (Sinapis alba and Camelina sativa cv Omega), collectively referred to as cultigens (Table 1). Ten days after sowing, plants were transplanted into $\varnothing 10$-cm plastic pots containing a peat substrate Kronen-Klasmann. Seedlings were grown on benches in a greenhouse at $21 / 16^{\circ} \mathrm{C}$ (day/night) and $10 \mathrm{~h}$ of light, fertilized and watered in accordance with the accepted practice for the species.

Three A. brassicicola isolates (X2038, X2039, $\mathrm{X} 2040$ ) used in this study were obtained from Geves Snes National Seed Testing Station, France. Thirteen isolates were collected in recent years from Brassicaceae 
crops symptomatic for dark leaf spot, grown in various regions of Poland (2011 to 2014). Pathogen identity was confirmed by microscopic observations of morphological characteristics. Stock cultures of A. brassicicola were maintained on standard Potato Dextrose Agar (PDA) media at $4{ }^{\circ} \mathrm{C}$. For the preparation of inoculum, each isolate was incubated on PDA at $24 \pm 1{ }^{\circ} \mathrm{C}$ in the dark. Conidia of 10-day old cultures were washed off the plate with sterile distilled water and filtered through two layers of cheesecloth to remove the remaining mycelium. The conidial suspension was then shaken and supplemented with $0.1 \%$ (w:v) agar solution. The inoculum concentration was determined by three-time measurements with a hemocytometer using a stereoscopic microscope Nikon Eclipse E200, and final inoculum concentrations were adjusted according to the protocols used in particular tests described below.

Pathogenicity and aggressiveness of all isolates were checked on the detached leaves of a susceptible cv. Kamienna Głowa (PNOS Ożarów, Poland). Leaves were detached with scissors from 45-day old plants and immediately placed on wet cellulose wadding in plastic boxes. Conidial suspension $(40 \mu \mathrm{l})$ at $10^{5} \times \mathrm{ml}^{-1}$ was placed in the center of the adaxial side of each leaf. The boxes with inoculated leaves were covered with glass to maintain stable and high $\mathrm{RH}$ (>85\%) and placed in the growth chamber at $25^{\circ} \mathrm{C}$ in darkness. Disease symptoms were assessed in two independent experiments, based on the size of necrotic lesions at 3 and 7 dpi. All 16 tested isolates were pathogenic, despite differences in their aggressiveness (Online Resource 1). In Poland, the major pathogen in the Brassicaceae crops is A. brassicicola: all of 21 isolates collected for this study from the symptomatic Brassica plants grown at InHort experimental fields, were identified as A. brassicicola or A. alternata. Moreover, testing the A. brassicae (three isolates from CBS-KNAW Collections, the Netherlands) proved negative, as they did not incite the dark spot symptoms on the tested pool of cultigens (data not presented), and none of isolates isolated from the field crops symptomatic for dark leaf spot was identified as A. brassicae.

For the subsequent bio-assays, the six most aggressive A. brassicicola isolates (X2038, X2039, X2040, IW1, IW6, IW11) were mixed in equal proportions, as they had similar virulence levels in the detached leaf assay on 10 tested cultigens (data not published). First, each isolate suspension was brought to the required concentration, then all six diluted isolate suspensions were mixed in equal volumes, and the final inoculum mix was recounted to ensure the appropriate conidial concentration.

Experiments conditions

\section{Bio-assay optimization}

Experiments were conducted under controlled environment conditions in the growth chambers of InHort. These assays included detached leaf and seedlings bioassays, described below. We evaluated the influence of several variables on the disease severity in cultigens with various levels of susceptibility to A. brassicicola: Inoculum concentration, leaf age and position, incubation temperature, and testing method (detached leaf; seedlings).

Four inoculum concentrations $\left(10^{3}, 10^{4}, 5 \times 10^{4}, 10^{5}\right.$ conidia $\mathrm{ml}^{-1}$ ) were tested for severity of disease symptoms in a detached leaf assay using four cultigens of Brassicaceae plants (PGH01C, PGH05I, PGH08C, Sinapis alba), each showing a different susceptibility to the pathogen as per our initial experiments. The $3 \mathrm{rd}$ or 4th fully expanded leaves taken from 45-day old plants of each cultigen were placed immediately in plastic boxes lined with moist tissue paper, and hand-sprayed over the leaf upper (adaxial) surface with a conidia suspension (see above) until completely covered. The boxes containing the inoculated leaves were covered with glass to maintain stable high $\mathrm{RH}(>85 \%)$ and then placed in a growth chamber at $25{ }^{\circ} \mathrm{C}$ in darkness. Each inoculum concentration was tested in a series of two independent experiments with 22 leaves per cultigen.

The effect of leaf age and plant age was assessed using the detached leaf assay. To obtain leaves of different ages, seeds were sown at 10-day intervals and two fully expanded leaves at the 3rd and 4th leaf position on a plant were collected from 35-, 45-, and 55-day old plants. Disease development as relevant to the leaf position on a plant was determined using two fully expanded leaves attaching at the $1 \mathrm{st}$ and $2 \mathrm{nd}$, 3rd and 4th, and 5th and 6th leaf positions, collected from 55-day old plants. Detached leaves were inoculated with conidia suspension $\left(10^{5}\right.$ conidia $\left.\times \mathrm{ml}^{-1}\right)$ and incubated as described above. We conducted two independent experiments, each consisting of two boxes containing 18 leaves (one leaf position per one box) for each of the 
four studied cultigens (PGH01C, PGH05I, PGH08C, and PGH33P).

The influence of incubation temperature $(18,22,25$, and $30{ }^{\circ} \mathrm{C}$ ) on disease intensity in the five studied cultigens (PGH01C, PGH05I, PGH08C, PGH33P, PGH34K) was evaluated using the seedlings tests and the detached leaf assay. The 45-day old seedlings were inoculated with conidial suspension $\left(10^{5}\right.$ conidia $\left.\times \mathrm{ml}^{-1}\right)$ until run-off, using a hand-sprayer. Inoculated plants were covered with polythene foil to preserve high humidity and incubated in a growth chamber $\left(25^{\circ} \mathrm{C}\right.$ day/ night, $12 \mathrm{~h}$ photoperiod). We performed a similar study using the leaves (3rd and 4th) detached from 45-day old plants, using the methods described above. The experiment was designed in two independent replicates. The number of seedlings or leaves used in the test differed for each cultigen and for each incubation temperature due to availability of plant materials ( $n=12$ to 20$)$, in particular for the interspecific hybrids ( $n=10$ to 20 ), and was considered in the post-hoc statistical analyses.

To compare the two methods of inoculation, $38 \mathrm{cul}-$ tigens of Brassicaceae plants (Table 1) were evaluated with the detached leaf and seedlings tests. Head cabbage line PGH23K was used as the susceptible control, and S. alba (white mustard) and Camelina sativa (camelina) were used as the resistant controls.

In the detached leaf assay, the disease severity was examined on two leaves (3rd, 4th true leaves) detached from 45-day old plants. The severity of disease symptoms on seedlings was evaluated after inoculating 45day old seedlings. The experiment was conducted as two replications of independent sets, and each cultigen was represented by 15-20 seedlings/leaves depending on the material availability within each cultigen.

\section{Field evaluations}

A collection of 27 cultigens including $B$. oleracea (head cabbage, cauliflower), B. rapa (Chinese cabbage), $B$. napus (rapeseed), and interspecific hybrids at various degrees of homozygosity, with diverse morphological and agro-botanical characteristics, was evaluated in 2012 at the experimental field area (Department of Genetics, Breeding, and Biotechnology, InHort). A subset of 11 of these cultigens was subjected for additional field testing (single repetition) in 2015.

The soil type was a pseudopodsolic over loamy sand (1.5\% organic matter, $\mathrm{pH} 6.5$ ). The tested plants were grown from seeds in the greenhouse in May. Three weeks-old seedlings were planted in the field, with $50 \mathrm{~cm}$ between plants in the row and $60 \mathrm{~cm}$ between the rows. The design was a randomised complete block with three replications. Plots consisted of 10 plants in a single row. Fertilisation, irrigation, and pest control followed the current recommendations for cabbage production. No fungicides were applied during the vegetation period, for evaluation of resistance of the cultigens.

\section{Disease ratings}

The degree of infection on detached leaves or seedlings was assessed four days after inoculation. The field trials were assessed gradually from mid-September until midOctober, when plants reached maturity. Disease intensity was rated using 0 to 5 scale: $0=$ no spots and no chlorosis on the investigated plant organ, $1=$ disease symptoms visible on up to $10 \%$ area of the investigated plant organ, 2 = disease symptoms visible on 11 to $25 \%$ area of the investigated plant organ, $3=$ disease symptoms visible on 26 to $50 \%$ area of the investigated plant organ, $4=$ disease symptoms visible on 51 to $75 \%$ area of the investigated plant organ, $5=$ disease symptoms visible on more than $76 \%$ area of the investigated plant organ. The disease severity index (DSI) was calculated for each cultigen as a mean of the ratings determined for the seedlings/leaves, respectively, similar to other studies of this pathosystem (Hansen and Earle 1997; Doullah et al. 2006).

At the beginning of this study, such arithmetically biased methods of assessment of Alternaria dark leaf spot severity were commonly employed, and keep on being used until this day (Conn et al. 1990; Deep and Sharma 2012; Doullah et al. 2006; Hong and Fitt 1995; Köhl et al. 2010; Mazumder et al. 2013; Rashid et al. 2011; Scholze and Ding 2005; Sharma et al. 2002; Sharma et al. 2004), although more accurate methods were developed (Brazauskienè et al. 2011; Meena et al. 2011; Meena et al. 2016; Shrestha et al. 2005). Moreover, the relative disease intensity on the cultigens undergoing testing (and, hence, their inferred resistance) would be kept, irrespective of the scale used for such an assessment. Cultigens with a DSI of 0 to 1 were classified as highly resistant, those with a DSI of 1.1 to 2 as moderately resistant, and those with an index of 2.1 to 5 as cultigens with various levels of pathogen susceptibility. 
Table 1 Brssicaceae cultigens tested in this study for Alternaria brassicicola resistance. Species, genetic background (if known), vegetation period [days], and DSI \pm SD in the seedling, detached leaf, and field assays are listed

\begin{tabular}{|c|c|c|c|c|c|c|}
\hline Cultigen $^{\mathrm{a}}$ & T-sd ${ }^{b}$ & $\mathrm{~T}-1 \mathrm{f}^{\mathrm{b}}$ & $\begin{array}{l}\mathrm{T}- \\
\text { field } 2012^{\mathrm{b}}\end{array}$ & $\begin{array}{l}\mathrm{T}- \\
\text { field } 2015^{\mathrm{b}}\end{array}$ & $\begin{array}{l}\text { Veg. period } \\
{\left[{ }_{\text {day }}\right]^{\mathrm{c}}}\end{array}$ & Background $^{\mathrm{d}}$ \\
\hline PGH01C & $3.1 \pm 0.8$ & $2.9 \pm 0.8$ & - & - & 60 & cauliflower Brassica oleracea var. botrytis DC \\
\hline PGH02C & $3.4 \pm 0.6$ & $4.1 \pm 0.7$ & $2.7 \pm 0.6$ & - & 70 & cauliflower Brassica oleracea var. botrytis DC \\
\hline PGH03C & $4.6 \pm 0.7$ & $4.4 \pm 0.6$ & $3.3 \pm 0.7$ & - & 60 & cauliflower Brassica oleracea var. botrytis DC \\
\hline PGH04C & $4.1 \pm 0.7$ & $4.4 \pm 0.6$ & $3.3 \pm 0.6$ & - & 60 & cauliflower Brassica oleracea var. botrytis DC \\
\hline PGH05I & $1.6 \pm 0.7$ & $1.7 \pm 0.7$ & $1.9 \pm 0.5$ & 1.7 & - & interspecific $B$. oleracea $\times$ B. napus $\mathrm{S}_{5}$ after $\mathrm{BC}_{2}$ \\
\hline PGH06I & $3.1 \pm 1.1$ & $3.2 \pm 0.7$ & - & - & - & interspecific $B$. oleracea $\times$ B. napus $\mathrm{S}_{5}$ after $\mathrm{BC}_{2}$ \\
\hline 'Bilko $F_{1}$ ' & $4.2 \pm 0.6$ & $4.6 \pm 0.6$ & $4.3 \pm 0.5$ & 4.5 & 70 & Chinese cabbage Brassica rapa var. pekinensis \\
\hline PGH08C & $3.1 \pm 1.2$ & $3.4 \pm 1.0$ & - & - & 85 & cauliflower Brassica oleracea var. botrytis DC \\
\hline PGH09K & $4.3 \pm 0.7$ & $4.6 \pm 0.5$ & $2.3 \pm 0.6$ & - & 120 & head cabbage Brassica oleracea var. capitata \\
\hline PGH10P & $3.1 \pm 0.5$ & $3.0 \pm 0.0$ & - & - & 55 & swede Brassica napus \\
\hline PGH11P & $3.6 \pm 0.5$ & $2.6 \pm 0.5$ & - & - & 55 & swede Brassica napus \\
\hline PGH12P & $3.7 \pm 0.6$ & $4.8 \pm 0.5$ & $4.7 \pm 0.6$ & - & 55 & Chinese cabbage Brassica rapa var. pekinensis \\
\hline PGH13R & $3.2 \pm 0.6$ & $3.5 \pm 0.8$ & $3.3 \pm 0.6$ & 3.1 & - & seedrape Brassica napus \\
\hline PGH14R & $4.0 \pm 0.8$ & $4.1 \pm 0.9$ & $3.0 \pm 0$ & 4.5 & - & seedrape Brassica napus \\
\hline PGH15R & $3.3 \pm 0.6$ & $3.3 \pm 0.7$ & $3.0 \pm 0$ & 4.7 & - & seedrape Brassica napus \\
\hline PGH16K & $3.0 \pm 0.7$ & $3.8 \pm 0.9$ & $3.3 \pm 0.6$ & - & 90 & head cabbage Brassica oleracea var. capitata \\
\hline PGH17K & $4.6 \pm 0.5$ & $4.5 \pm 0.7$ & $3.0 \pm 0$ & - & 90 & head cabbage Brassica oleracea var. capitata \\
\hline PGH18K & $3.7 \pm 0.5$ & $4.1 \pm 0.7$ & $3.7 \pm 0.6$ & - & 90 & head cabbage Brassica oleracea var. capitata \\
\hline PGH19K & $3.8 \pm 0.9$ & $4.4 \pm 0.7$ & $4.3 \pm 0.6$ & - & 90 & head cabbage Brassica oleracea var. capitata \\
\hline PGH20K & $4.0 \pm 0.6$ & $3.7 \pm 0.9$ & $3.3 \pm 0.6$ & - & 90 & head cabbage Brassica oleracea var. capitata \\
\hline 'Slawa z Enkhuizen' & $3.9 \pm 0.8$ & $4.4 \pm 0.5$ & $0.8 \pm 0.3$ & 0.9 & 62 & head cabbage Brassica oleracea var. capitata \\
\hline PGH22K & $3.7 \pm 0.8$ & $4.2 \pm 0.7$ & $2.3 \pm 0.6$ & 2.3 & 110 & head cabbage Brassica oleracea var. capitata \\
\hline PGH23K & $3.7 \pm 0.6$ & $4.3 \pm 0.6$ & $2.0 \pm 0$ & 2.4 & 110 & head cabbage Brassica oleracea var. capitata \\
\hline PGH24K & $3.3 \pm 0.8$ & $3.9 \pm 0.6$ & $1.4 \pm 0.1$ & - & 90 & head cabbage Brassica oleracea var. capitata \\
\hline PGH25I & $2.0 \pm 1$ & $1.8 \pm 0.6$ & - & - & - & interspecific $B$. oleracea $\times$ B. napus $\mathrm{S}_{5}$ after $\mathrm{BC}_{2}$ \\
\hline PGH26K & $3.4 \pm 0.6$ & $3.7 \pm 0.7$ & $3.1 \pm 0.6$ & - & 120 & head cabbage Brassica oleracea var. capitata \\
\hline PGH27I & $3.9 \pm 0.7$ & $3.8 \pm 0.4$ & - & - & - & interspecific $B$. oleracea $\times$ B. napus $\mathrm{S}_{5}$ after $\mathrm{BC}_{2}$ \\
\hline $\mathrm{PGH} 28 \mathrm{~K}$ & $2.1 \pm 0.7$ & $3.3 \pm 0.8$ & $2.7 \pm 0.6$ & - & 120 & head cabbage Brassica oleracea var. capitata \\
\hline PGH29K & $3.1 \pm 0.7$ & $3.7 \pm 0.7$ & $3.3 \pm 0.3$ & - & 120 & head cabbage Brassica oleracea var. capitata \\
\hline PGH30K & $3.5 \pm 0.6$ & $3.5 \pm 0.6$ & $2.7 \pm 0.5$ & 3.0 & 110 & head cabbage Brassica oleracea var. capitata \\
\hline 'Kamienna Glowa' & $4.0 \pm 0.4$ & $4.3 \pm 0.8$ & $4.4 \pm 0.3$ & - & 120 & head cabbage Brassica oleracea var. capitata \\
\hline 'Kilagreg $F_{1}$ ' & $3.7 \pm 0.7$ & $3.9 \pm 0.8$ & $1.3 \pm 0.6$ & 1.2 & 65 & head cabbage Brassica oleracea var. capitata \\
\hline PGH33P & $3.2 \pm 0.8$ & $3.5 \pm 0.8$ & - & - & 60 & Chinese cabbage Brassica rapa var. pekinensis \\
\hline PGH34K & $2.1 \pm 0.5$ & $2.2 \pm 0.6$ & - & - & 85 & head cabbage Brassica oleracea var. capitata \\
\hline PGH35C & $3.3 \pm 0.7$ & $2.8 \pm 0.7$ & $2.3 \pm 0.4$ & 2.4 & 85 & cauliflower Brassica oleracea var. botrytis DC \\
\hline PGH36K & $3.9 \pm 0.9$ & $4.3 \pm 0.6$ & $1.7 \pm 0.4$ & - & 70 & head cabbage Brassica oleracea var. capitata \\
\hline Camelina sativa & $0.0 \pm 0.0$ & $0.0 \pm 0.0$ & - & - & - & wild accession \\
\hline Sinapis alba & $0.4 \pm 0.2$ & $0.6 \pm 0.7$ & - & - & - & wild accession \\
\hline
\end{tabular}

${ }^{a}$ Cultigen's commercial names or codes used during breeding of these materials at InHort are presented. Bolded are the popular commercial cultivars and resistance standards

${ }^{\mathrm{b}}$ Cultigen's DSI \pm SD in the seedlings test (T-sd), detached leaf test (T-lf), and in the field under natural epidemics (T-field) in years 2012 or 2015. Details are described in the Materials and methods section. -: not determined. HSD (Tukey) for T-sd and T-pl (two-way-ANOVA): 0.707. HSD (Tukey) for T-field2012 (one-way-ANOVA): 1.521. Correlation analyses resulted in $r=0.921$ for T-sd vs. T-lf; 0.408 for Tfield 2012 vs. T-lf; and 0.244 for T-field 2012 vs. T-sd

${ }^{\mathrm{c}}$ Vegetation period from planting to harvest maturity

${ }^{\mathrm{d}}$ Species and genetic information (when available) are listed out 
Biochemical and molecular analyses

Plant growth, testing, and sampling

Twenty seedlings per each tested cultigen ( $S$. alba, 'Kamienna Głowa', PGH05I, and PGH09K) were grown from seeds for 45 days, and then inoculated with suspension of mixed A. brassicicola isolates and tested as per the optimized protocol (see Results). Each day, samples were collected from two plants per cultigen, at the same time ( $\sim 11 \mathrm{am})$. At $3 \mathrm{dpi}$, 'Kamienna Głowa' started showing mild Alternaria dark spot symptoms, which exacerbated at $4 \mathrm{dpi}$; hence, sampling was stopped at this time. Collected samples were snapfrozen in liquid nitrogen and stored at $-80{ }^{\circ} \mathrm{C}$ until extracted.

\section{Biochemical assays}

The homogenized samples were processed as in Nowicki et al. 2016: Extraction of soluble proteins (supernatant) was done with $5 \times(\mathrm{v}: \mathrm{w}) 50 \mathrm{mM}$ potassium phosphate, $\mathrm{pH} 7.2$, whereas the reactive oxygen species (ROS) and free phenols were assayed from the methanolic extracts $\left(18,000 \times g\right.$ for $15 \mathrm{~min}$ at $4{ }^{\circ} \mathrm{C}$ each, with $10: 1$ (v:w) of $80 \%$ methanol in water), supernatants combined, and pellets were used for lignin assessment.

\section{Assessment of $\mathrm{ROS}$ generation $\left(\mathrm{H}_{2} \mathrm{O}_{2}, \mathrm{HO}^{*}\right.$, and $\left.\mathrm{O}_{2}^{-}\right)$}

Generation of either ROS species followed the published methods (Loreto et al. 2001; Loreto and Velikova 2001; Habu and Ibeh 2015; Moukette et al. 2015). Methanolic extracts were assayed at $A_{390}, A_{560}$, and $\mathrm{A}_{530}$ for $\mathrm{H}_{2} \mathrm{O}_{2}, \mathrm{HO}^{*}$, and $\mathrm{O}_{2}{ }^{-}$, respectively. We used $\mathrm{H}_{2} \mathrm{O}_{2}$ as one of the standards; in the $\mathrm{HO}^{*}$ and $\mathrm{O}_{2}{ }^{-}$ assays, the absorbance readout was recalculated per $\mathrm{mg}$ of fresh tissue.

\section{Assessment of plant red-ox enzymic activities}

To analyze the dynamics of polyphenol oxidase (PPO), peroxidase (POX), superoxide dismutase (SOD), polygalacturonase (PGA), and catalase (CAT), we used the methods published elsewhere (Korgan et al. 2011; Moukette et al. 2015; Sheehy et al. 1988). Bufferextracted samples (see above) were assayed for protein using the BCA kit (Novazym, Poznań, Poland), and analyzed for linear assay range on a randomly chosen sample ( 0 dpi). Proper assays were run in microtiter plates for 3 to $5 \mathrm{~min}$, respectively, whereas absorbance readouts were recorded every minute in the Epoch2T reader (BioTek Instruments, Inc., Bad Friedrichshall, Germany). Protein activity was calculated as change in absorbance per minute and per mg of protein (PPO) or metabolized substrate/min/mg protein (POX, SOD, PGA, CAT).

\section{Accumulation of free phenols and deposition of lignins}

Levels of lignins deposition and free phenolics were assessed with published spectrophotometric methods (Campbell and Ellis 1992; Cvikrova et al. 1992). Methanolic extracts (see above) and pellets were used, and the assays used technical lignins and gallic acid as the respective standards.

Microscopic visualization of the infection process

Samples of the tested cultigens (susceptible: PGH09K, PGH12P, PGH33P, 'Kamienna Głowa' and (moderately) resistant: PGH05I and C. sativa; Table 2) were taken using a paper punch $(\varnothing 5 \mathrm{~mm}$; at least 10 samples per stage and per cultigen) at 0 to 4 days from plants inoculated with isolate X2039 (seedlings assay). Ethanol-cleared samples were re-hydrated by soaking in decreasing ethanol solutions (100, 75, and 50\% ethanol, $v / \mathrm{v}$ ). The conventional dual-stain followed a previously described protocol (Nowicki et al. 2012a): Re-hydrated samples were soaked in $0.05 \%$ trypan blue $(w / v$; CarlRoth Poland, aq) overnight at room temperature, then washed three times with distilled water $(5 \mathrm{~min}$, room temperature), and finally soaked in $0.05 \%$ aniline blue (w/v; Sigma-Aldrich Poland) in $150 \mathrm{mM} \mathrm{KH}_{2} \mathrm{PO}_{4}$, pH 9 for 3 to $4 \mathrm{~h}$, RT. The samples were then de-stained in $150 \mathrm{mM} \mathrm{KH}_{2} \mathrm{PO}_{4}, \mathrm{pH} 9$, three times for $15 \mathrm{~min}$, and mounted with water for microscopic observations.

The protocol for visualization of actin filaments was established after testing several available methods (Chang and Nick 2012; Kobayashi et al. 1997; Langenberg 1978; Maisch and Nick 2007; Miklis et al. 2007; Olyslaegers and Verbelen 1998; Opalski et al. 2005; Vitha et al. 2000). Based on the results of this initial study, we chose to follow the method of Olyslaegers and Verbelen (1998) after minor modifications. Samples were fixed immediately after collection, in mixture of $1 \%$ formaldehyde (prepared freshly; $w / v$ ), $0.05 \%$ glutaraldehyde $(v / \mathrm{v}), 2 \%$ glycerol $[v / v]$, and $1 \%$ 
DMSO $[\mathrm{v} / \mathrm{v}]$ in fixation buffer (50 mM PBS, $\mathrm{pH} 6.9$, $1 \mathrm{mM}$ EDTA, $2 \mathrm{mM} \mathrm{MgCl}_{2}$,) for $30 \mathrm{~min}$ at RT. After washing with the fixation buffer (no aldehydes), excess aldehydes were quenched with freshly prepared $\mathrm{NaBH}_{4}$ $(2 \mathrm{mg} / \mu \mathrm{l}, \mathrm{aq})$, and samples were permeabilized with Triton X-100 in wash buffer (1\% v:v; $30 \mathrm{~min}, \mathrm{RT})$. After three additional washes in $50 \mathrm{mM}$ PBS $\mathrm{pH} 7.4 \mathrm{pH} 7.4$; 5 min, RT, samples were soaked overnight $\left(4{ }^{\circ} \mathrm{C}\right.$; in darkness) with $0.66 \mu \mathrm{M}$ phalloidin-rhodamine (SigmaAldrich Poland) and $0.05 \%(w / v)$ aniline blue. Samples were then washed with $50 \mathrm{mM}$ PBS pH 7.4 and mounted with water for microscopic observations.

Confocal laser scanning microscopy was performed using a Nikon C1 microscope equipped with solid-state and diode lasers. Image acquisition of dual trypan blue aniline blue stained samples was performed in a sequential mode to avoid spectral cross-talk. For fluorescence excitation of trypan blue, $488 \mathrm{~nm}$ of Sapphire solid-state laser (Coherent) was used in a single-track mode. Fluorescence was collected through a filter block with a $650 \mathrm{~nm} \mathrm{LP}$ emission filter. For the aniline blue channel, the $408 \mathrm{~nm}$ excitation line of a diode laser was used in a single track mode. Fluorescence was collected through a filter block with a 513-530 nm BP emission filter. Fluorescence of rhodamine was induced using $543 \mathrm{~nm} \mathrm{He} / \mathrm{Ne}$ laser and collected through $605 / 675 \mathrm{~nm}$ emission filter. Z-series images were collected at $0.7-1 \mu \mathrm{m}$ intervals through the specimens. All images were processed using EZ C1 FreeViewer (v.3.90; http://nikon-ez-c1-freeviewer.software. informer.com/); the digital quantifications were performed using ImageJ (Abràmoff et al. 2004). Rendering of the 3D papilla structures from microscopic Z-stacks was done with Blender ver.2.74 and GIMP ver.2.8.2.

\section{Statistical analyses}

Data from both independent experiment sets were compared pairwise, for each variable undergoing optimization (age of leaf, leaf position, inoculum concentration, and bio-assay temperature). Statistical analyses indicated similarity of both independent sets for each variable tested: the F-tests always resulted in $P>0.74$ and the two-way ANOVA results showed the same significance levels for singular variables and their interactions. This permitted combing the data from both sets for analyses presented below. As each variable to be optimized (Figs. 1, 2, and 3) included at least one resistant cultigen, this deviated the DSIs from normality, hence, neither the separate datasets nor the combined dataset were checked for normality.
Computation and data comparisons were performed using MS Excel 2007 and R (ver. 3.2.0). Descriptive statistics employed calculation of means, standard deviations (SD), medians, quartiles, etc. Data comparisons were performed by one- or two-way-ANOVA (confidence level 0.95), with post-hoc Tukey's Honestly Significant Difference (HSD; $\alpha=0.05$ ) analyses. Values of $\mathrm{F}$ and $P$ for all ANOVA analyses are reported along the respective data.

Data availability All bio-assay data generated during this study are included in this published article and its supplementary information file. The detailed biochemical, molecular, and microscopic data generated during this study are available from the corresponding authors on reasonable request.

\section{Results}

Bio-assay optimization

For optimization of the inoculum concentration, four concentrations $\left(10^{3}, 10^{4}, 5 \times 10^{4}\right.$, and $10^{5}$ conidia $\times$ $\mathrm{ml}^{-1}$ ) were tested. Due to lack of significance for the interaction cultigen $\times$ inoculum concentration $(\mathrm{F}=$ $0.578 ; P=0.63)$, main effects of both factors were investigated separately with one-way-ANOVA and posthoc Tukey tests. Disease severity increased as the inoculum concentration increased above $10^{3}$ conidia $\mathrm{x} \mathrm{ml}^{-1}$ on all tested cultigens regardless of their susceptibility to A. brassicicola, except $S$. alba (Fig. 1). Our data shows lack of significant differences between the disease severity recorded at the two highest conidial concentrations $(\mathrm{F}=2.854, P=0.093)$. The critical inoculum concentration appeared to be $5 \times 10^{4}$ conidia $\mathrm{x} \mathrm{ml}^{-1}$, since only here and under higher concentration of $10^{5}$ conidia $\mathrm{x} \mathrm{ml}^{-1}$, the pathogen evoked modest disease symptoms in the resistance standard S. alba. Based on the data, either of the two highest inoculum concentrations can be used for reliable testing, and the subsequent bio-assays employed the $10^{5}$ conidia $\times \mathrm{ml}^{-1}$ inoculum concentration.

Experimental results indicated that leaf age $(P<0.001)$ and genotype $(P<0.001)$, as well as their interaction $(P<0.001)$ had significant effects on disease intensity levels among the tested cultigens (Fig. 2A). The older leaves exhibited more symptoms than the younger leaves, irrespective of the cultigen 


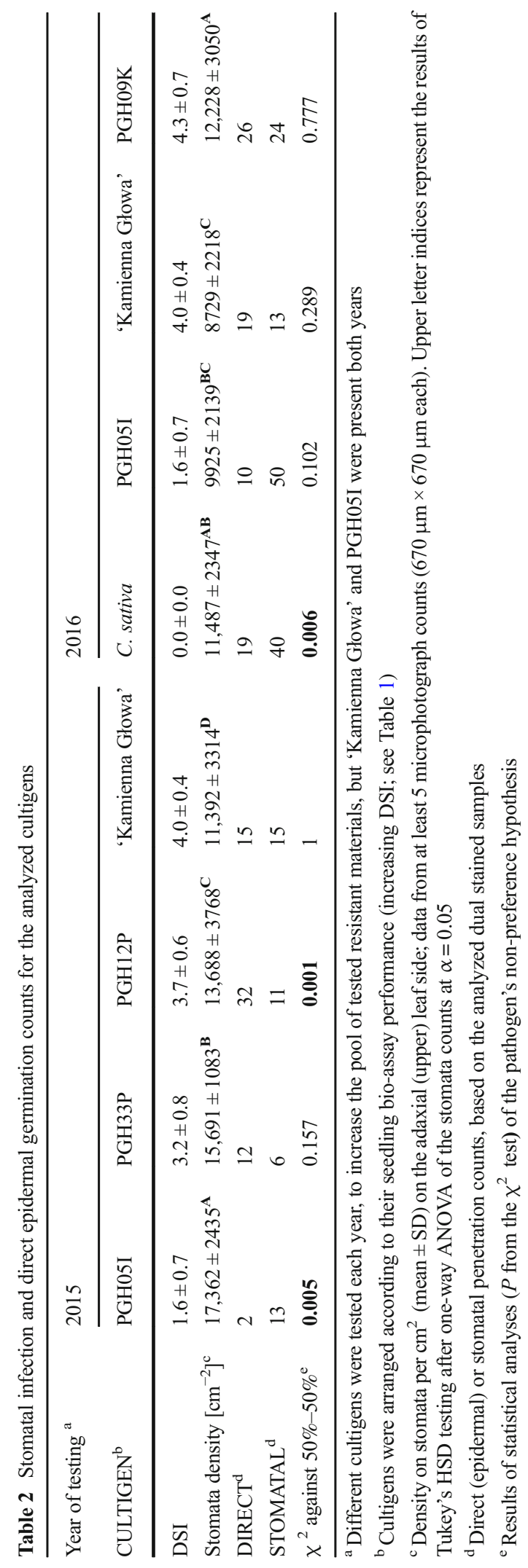

susceptibility to A. brassicicola. For all cultigens, the leaves of 35-day old plants exhibited less disease symptoms than those from the 45- or 55-day old plants (for cultigens: $P<0.001$; for $35 / 45$-day old and older: $P<0.001$; for interaction cultigen $\times$ age: $P<0.05$ ). Since the DSIs of PGH08C and PGH33P lacked significant differences from each other at 45- or 55-day old, the ranking of the cultigens resistance would not be affected by selecting leaves at these stages. For all further assays, leaves from 45-day old plants were used, to reduce the length of experiments.

We observed significant effects of leaf position $(P<0.001)$, genotype $(P<0.001)$, and their interaction $(P<0.001)$ on disease intensities among the tested cultigens (Fig. 2B). This held for all tested cultigens, with the oldest detached leaves (1st and 2nd leaves) displaying more intense disease symptoms compared with the younger ones. For cultigens PGH05I and PGH08C, the DSIs lacked significant differences between the oldest leaves (1st and 2nd leaves) and middle ones (3rd and 4th leaves), whereas for the cultigens PGH01C and PGH33P, significantly higher DSIs were recorded on the oldest leaves, compared with the younger stages tested. Based on these results, we chose testing the $3 \mathrm{rd}$ and 4 th leaves in the subsequent experiments, as to limit the susceptibility groups that arise.

Data on the seedlings and detached leaf bio-assays under temperatures $18,22,25$, or $30^{\circ} \mathrm{C}$ suggest a significant effect of this parameter on disease intensity, regardless of the A. brassicicola susceptibility of the cultigen (Fig. 3). In the seedlings tests, the DSI values for $25^{\circ} \mathrm{C}$ differed significantly from a lower DSI noted for $18{ }^{\circ} \mathrm{C}$ regardless of the cultigen tested, exceeding slightly the DSI for either $22{ }^{\circ} \mathrm{C}$ or $30{ }^{\circ} \mathrm{C}$. For the detached leaf tests (Fig. 3A), ANOVA indicated that incubation temperature had no effect on disease severity for most of the tested cultigens $(P>0.05)$. The significant differences between various incubation temperatures were apparent only for the cultigen PGH33P ( F = $27.8526, P<0.001)$. In case of other cultigens, there was either no significant difference among temperatures (PGH01C: $P>0.05$; PGH05I: $P>0.05$; PGH08C: $P>0.05$ ), or significant differences in symptom severity were recorded only between $18^{\circ} \mathrm{C}$ and $25^{\circ} \mathrm{C}$ (PGH34K: $P<0.001)$. Based on our data, the $A$. brassicicola selection can be conducted at 22 or $25{ }^{\circ} \mathrm{C}$ with either testing method. For subsequent testing, we chose the $25^{\circ} \mathrm{C}$ as the assay temperature optimum. 


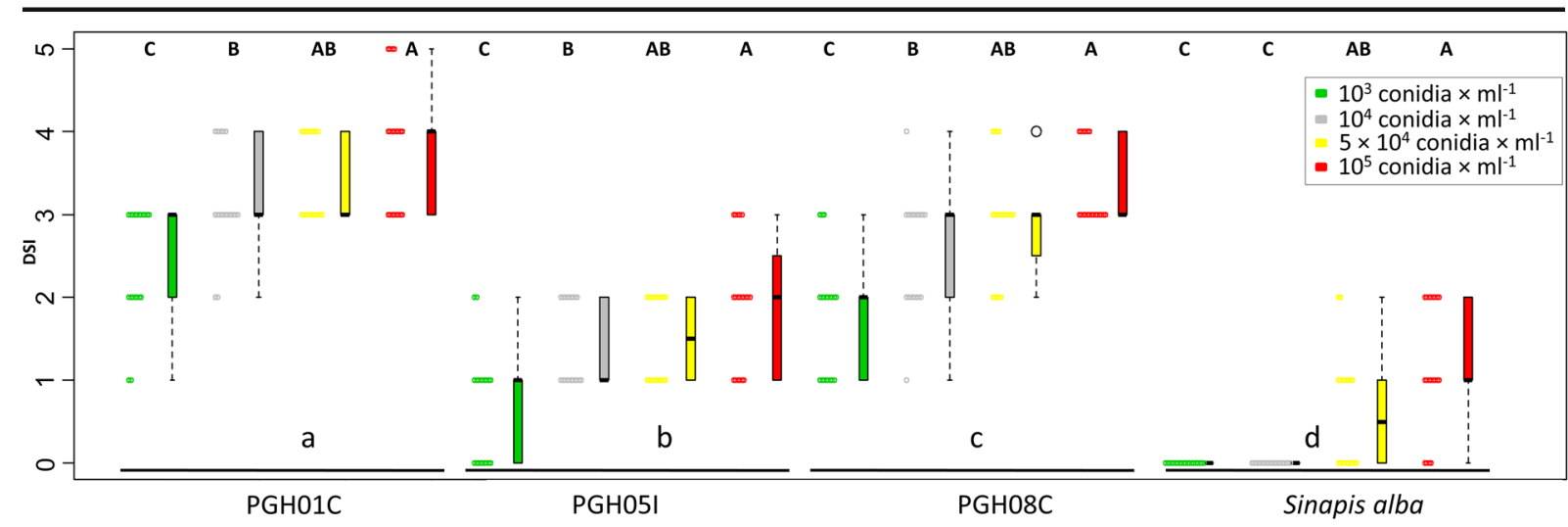

Fig. 1 Impact of inoculum concentration on the Alternaria dark spot severity of the investigated cultigens. Raw data for disease intensity of each cultigen tested (see also Table 1) are presented as a series of stacked beeswarms in colors representing various inoculum concentrations tested (described in the legend), juxtaposed with the respective boxplots (median is marked in black; boxes represent the interquartile range; whiskers extend to cover the rest of the data in each group; outliers are represented as empty

\section{Comparison of two laboratory testing methods}

Disease severity was compared in 38 cultigens of brassicas employing two bio-assays under optimized parameters (seedlings and detached leaf assays; Table 1). Comparison of these assays results (twoway-ANOVA) indicated that the two methods did not significantly differ in evaluating the cultigen resistance against $A$. brassicicola $(P=0.134)$. It is important to note, that the DSIs of only four cultigens (PGH11P, PGH12P, PGH19K, and PGH28K) exhibited significant differences $(P<0.05$; results of separate pairwise comparisons of these four cultigens) between the seedlings assay and the detached leaf assay. Correlation analysis on the mean DSIs for each cultigen in the leaf and seedling bio-assays $\left(r^{2}=0.921\right)$ indicated that either method may be used for preliminary screening, as in our study, whereas the cultigen utility must be confirmed in further breeding steps.

ANOVA revealed a significant effect of the cultigen $(P<0.001)$, driving the impact of the interaction of cultigen $\times$ testing method $(P<0.001)$ on the disease severity. From among 38 cultigens tested using both methods, two cultigens PGH05I and PGH25I displayed the lowest disease symptoms, followed by PGH34K and PGH28K (Table 1). The remaining cultigens showed various degrees of susceptibility to A. brassicicola in both, the detached leaf assays and the seedlings assays. white circles). Due to lack of significance for the interaction cultigen $\times$ inoculum concentration $(P=0.63)$, the main effects of both factors were investigated separately with one-way-ANOVAs and post-hoc Tukey HSD tests $(\alpha=0.05)$. Capital letters denote the post-hoc grouping for inoculum concentration (HSD: 0.51); small letters - post-hoc grouping for cultigen of significantly different reaction to A. brassicicola (HSD: 0.323)

From the two resistance standards tested, S. alba showed barely any disease symptoms, whereas C. sativa remained free of the dark leaf spot symptoms.

\section{Field evaluations and test cross-comparison}

Twenty seven Brassicaceae cultigens were tested in the field in 2012, and 11 were tested in 2015, and showed a broad range of dark leaf spot severity (Table 1). The lowest DSI values were obtained for 'Sława $\mathrm{z}$ Enkhuizen' $(0.8 \pm 0.3)$, 'Kilagreg $\mathrm{F}_{1}$ ' $(1.3 \pm 0.6)$, and PGH24K (1.4 \pm 0.1$)$. Six other cultigens (PGH36K, PGH05I, PGH23K, PGH09K, PGH35C, and PGH22K) expressed slightly higher, but still relatively low disease severity (from 1.7 to 2.3 ). The highest disease severity in 2012 was observed for 'Bilko $F_{1}$ ', PGH12P, PGH19K, and 'Kamienna Głowa', whereas in 2015 for PGH15R, PGH14R, and 'Bilko $F_{1}$ '. Ratings for the remaining cultigens tested in the field ranged from 2.7 to 3.3, representing a rather narrow range.

When comparing the bio-assays results with the field data (Table 1), it was apparent, that 13 cultigens (Tfield2012) differed in response to A. brassicicola. Based on the statistical model generated by the two-way ANOVA, the genotype had a higher effect on the disease intensity $(P<0.001)$ than the testing method used for evaluation $(P<0.001)$, driving the interaction of both factors $(P<0.001)$. Lower DSIs in the field than in the 


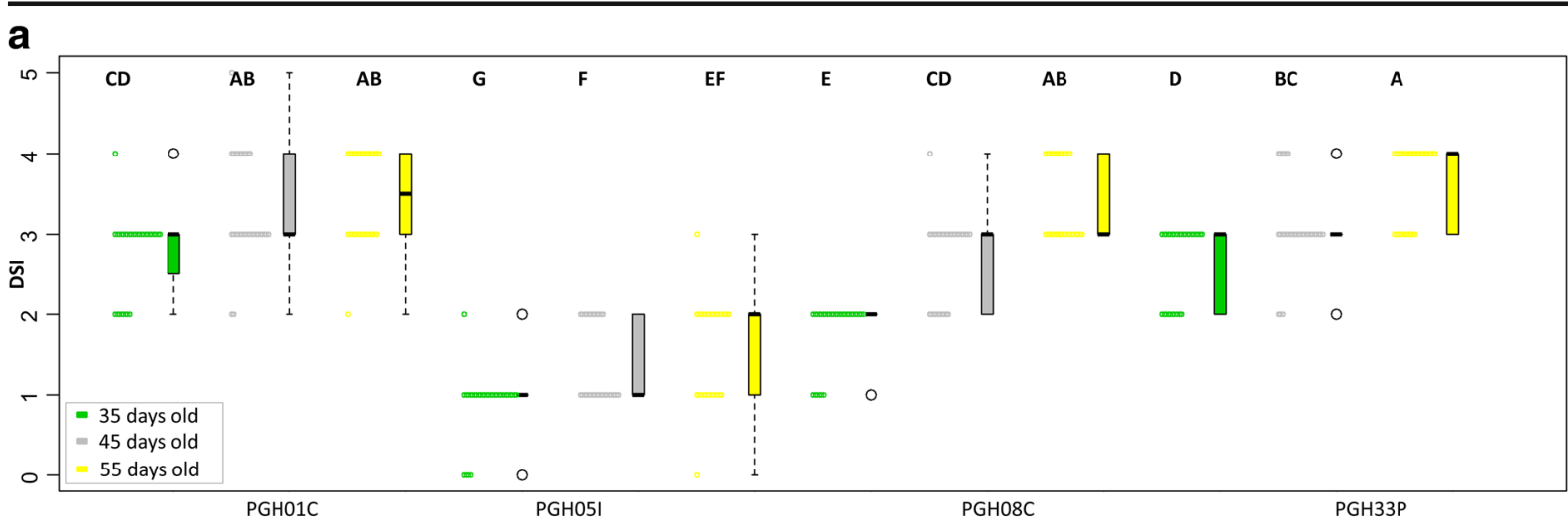

b

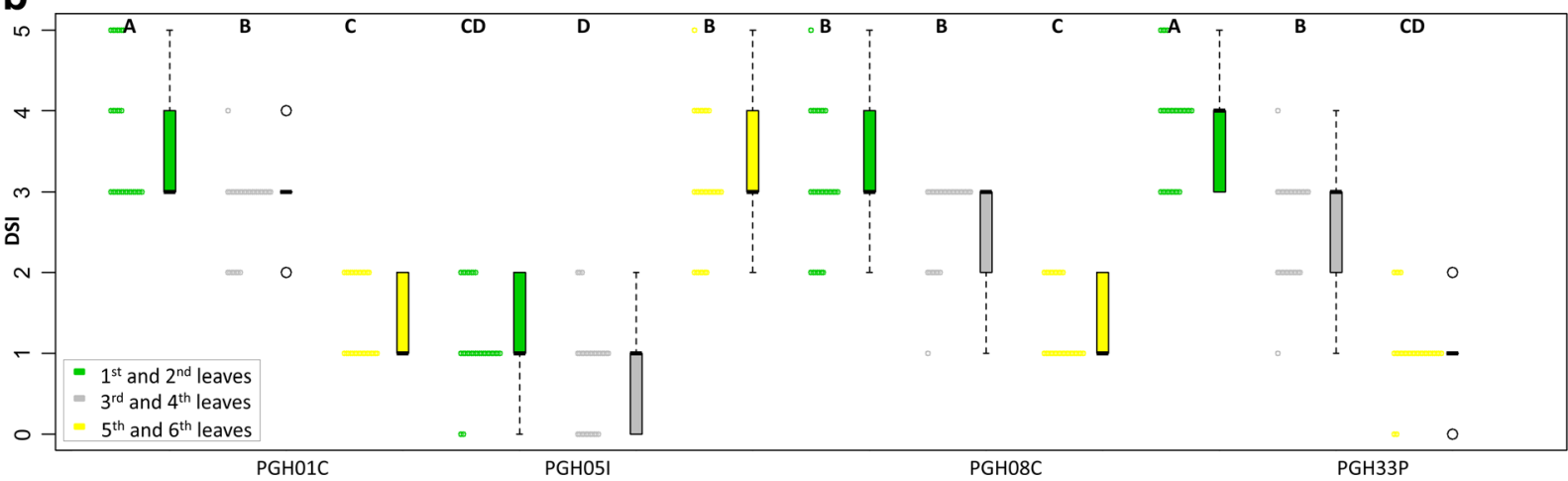

Fig. 2 Effect of leaf age (A) and position (B) on Alternaria dark spot severity in the tested cultigens. Raw data for disease intensity of each cultigen tested (see also Table 1) are presented as series of stacked beeswarms in colors representing leaf age tested or position tested (described in the respective legends), juxtaposed with respective boxplots (median is marked in black; boxes represent

bio-assays were observed for majority of cultigens tested (PGH09K, PGH22K, PGH23K, PGH24K, PGH30K, 'Kilagreg F ', PGH36K, PGH35C, 'Sława z Enkhuizen', PGH02C, PGH03C, PGH04C, and PGH17K), whereas only PGH05I showed an inverse behavior, with worse field than laboratory performance, yet of small effect in terms of the biological impact. Correlation analyses between the field results and either leaf or seedling bio-assays confirmed this result $\left(\mathrm{r}^{2}=\right.$ 0.408 or 0.244 , respectively; only cultigens analyzed under all three testing methods were included here; Table 1). Thus, due to the low but noticeable DSI changes under different testing methods and regardless of the results of the laboratory screens, resistance breeding should be confirmed under field epidemics.

In summary, we optimized several parameters important for standardizing two bio-assays of Brassicaceae cultigens with relation to their response to A. brassicicola inoculation. In the course of this the interquartile range; whiskers extend to cover the rest of the data in each group; outliers are represented as empty white circles). Capital letters denote grouping according to the Tukey tests post two-way-ANOVA (leaf age $(A)$ or position $(B) \times$ cultigen). HSD for leaf age $\times$ cultigen: 0.423 . HSD for leaf position $\times$ cultigen: 0.555

study, we confirmed the inverse relationship between plant (leaf) age and A. brassicicola resistance. Comparison of both testing methods (seedlings and detached leaf) with the field data using a broad array of cultigens indicated that: (i) under controlled conditions, the genotype rather than the testing method underlies the cultigen's resistance; (ii) the stringent conditions of our optimized laboratory screens allowed to reliably distinguish the (moderately) resistant cultivars from the susceptible ones; and (iii) field assays confirmed the particularly good performance of the line PGH05I, despite minor DSI differences.

Microscopic analyses of the A. brassicicola infection process

After optimizing the main parameters for the bio-assays, we sampled the ongoing experiments for comparative 


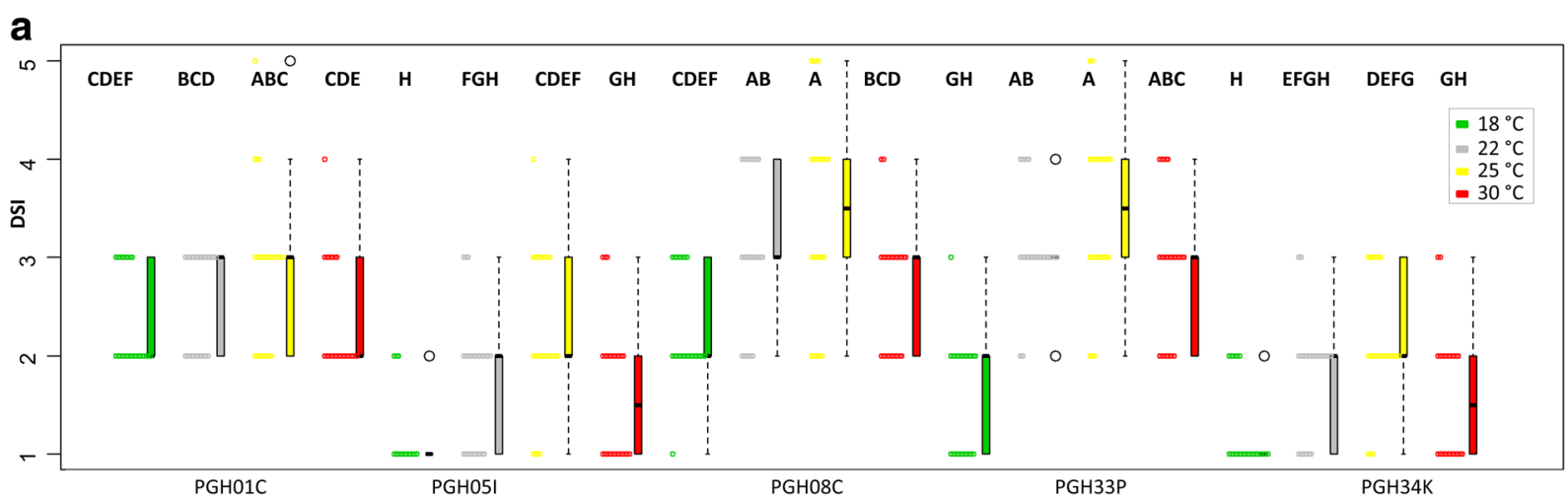

b

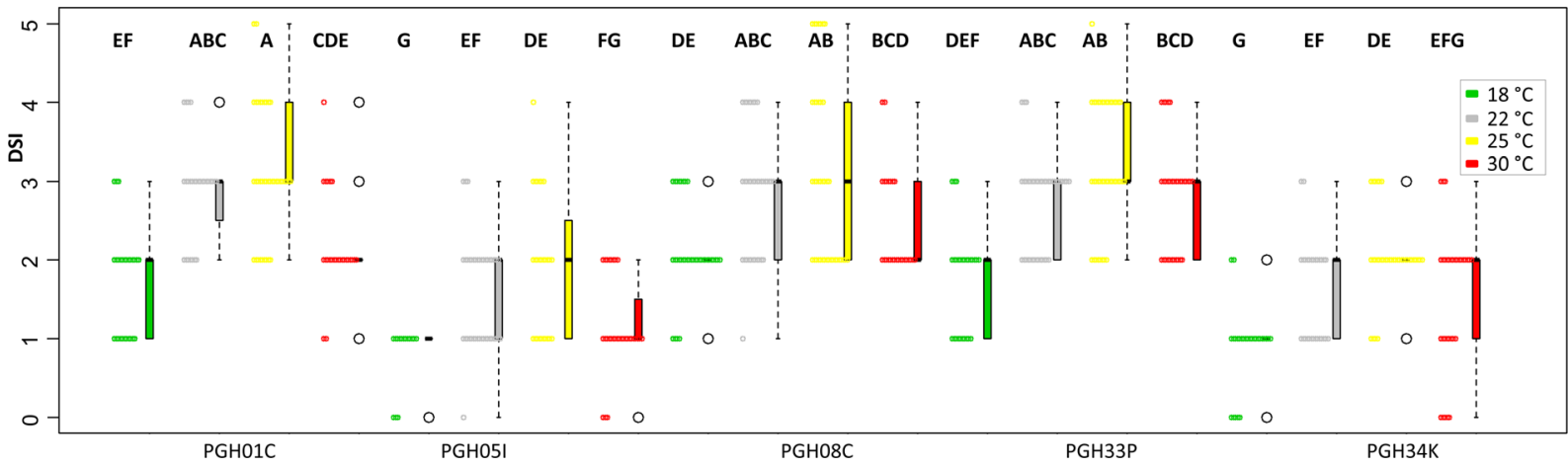

Fig. 3 Influence of incubation temperature on Alternaria dark spot severity in chosen cultigens. (A) Detached leaf test. (B) Seedlings test. Raw data for disease intensity of each cultigen tested (see also Table 1) are presented as series of stacked beeswarms in colors representing the incubation temperature tested in either assay (described in the respective legends), juxtaposed

microscopic analyses of the infection process in plant materials differing in response to A. brassicicola. Confocal microscopic analyses of dually stained samples visualized the subcellular events following the pathogen inoculation.

Staining of chitin in the pathogen cell wall with trypan blue, and of callose deposited in the host plant papillas with aniline blue, visualized the interactions between the pathogen and the host plants. Various stages of pathogen infection (germinating conidia, aerial hyphae growth, epidermal and stomatal penetrations, establishment of haustoria and secondary hyphae) together with the plant defense against infection (papilla depositions) were observed (Fig. 4). These analyses showed that $A$. brassicicola invades the leaf surface by means of both, direct penetration and stomata growth. Detailed counting of the penetration events suggested a novel hypothesis on the relationship between plant susceptibility status and the penetration mode assumed by with respective boxplots (median is marked in black; boxes represent the interquartile range; whiskers extend to cover the rest of the data in each group; outliers are represented as empty white circles). Capital letters denote grouping according to the Tukey tests post two-way-ANOVA (incubation temperature $\times$ cultigen), for both kinds of assays. HSD for (A): 0.652. HSD for (B): 0.663

the pathogen. The susceptible plants tested were predominantly infected by direct hyphae growth or penetration through appressorium, with only occasional stomatal infection (PGH12P; $P=0.0014 ; n=43$ ) or lacked significance in the preference to the infection mode (PGH33P, 'Kamienna Głowa'; Table 2). Contrastingly, the defenses raised by PGH05I with the lowest DSI, necessitated the pathogen to penetrate through the stomata instead $(P=0.005 ; n=15)$. These differences are unlikely to be explained by the increased number of stomata in this resistant cultigen (Table 2), as even including the increased stomata density in this line into the $\chi^{2}$ test only slightly weakens the result $(P=0.07$ for 11 stomatal vs. 4 direct penetration attempts). Papilla deposition or size lacked statistical differences in relation to plant susceptibility level (PGH12P: $119.62 \pm$

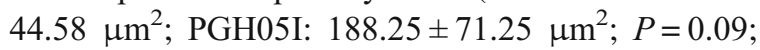
Fig. 4 and papilla sizes data not shown). Taking into account the lack of differences in papilla size or 

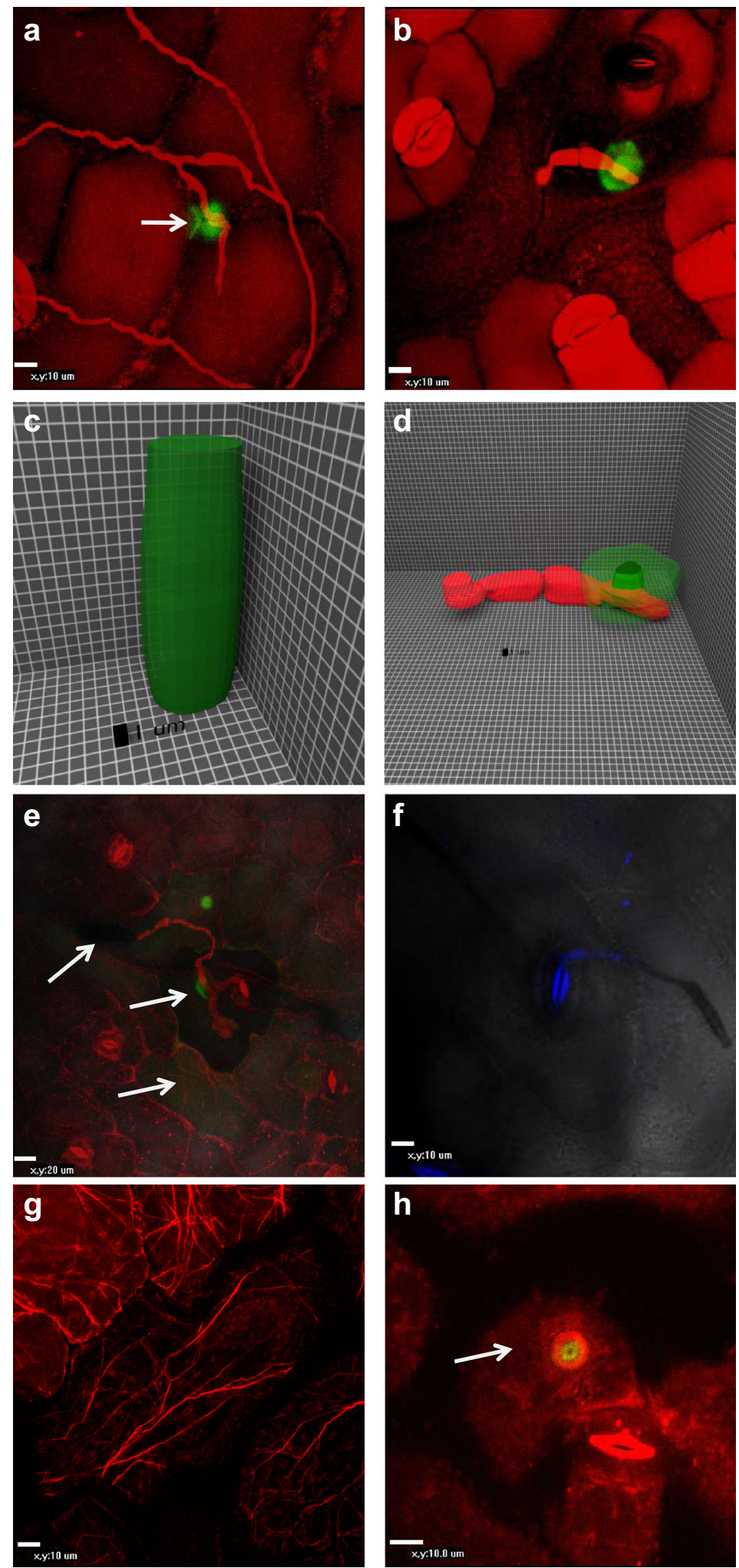
Fig. 4 Confocal microscopic analyses of the Alternaria brassicicola - cabbage pathosystem. Dually stained samples visualize the infection process (trypan blue [red or blue channel] + aniline blue [green channel]: A,B,F; rhodaminephalloidin [red channel] + aniline blue [green channel]: E,G,H; computer rendering of confocal dually stained Z-stacks: C,D). A: Successful infection of the leaves of susceptible cultigen PGH12P, upon growing through the deposited papilla (indicated by arrow). B: Hyphae made to extend, when it failed to grow through the papilla of the resistant cultigen PGH05I. C: 3D rendering of a papilla representative for the susceptible cultigen PGH12P. D: 3D rendering of a papilla representative for the resistant cultigen PGH05I. A smaller number of stacked pictures generated a shorter papilla. E: Visualization of a successful infection of the susceptible cultigen PGH12P at 4 dpi. Arrows from left to right denote: Germinating conidium; successful direct penetration and overcoming plant defenses - development of haustoria and secondary hyphae; reaction of the neighboring cells: strands of stained actin drive the deposition of callose cloak to prevent spread of the infection. F: Stomatal infection on the resistant cultigen PGH05I at 4 dpi. G: Typical actin networks crossing cells of the uninfected leaves (presented: susceptible cultigen PGH12P at 0 dpi). H: Rapid polarization of the actin networks, tightly surrounding the papilla deposited beneath the perceived pathogen attack (presented: resistant cultigen PGH05I at $2 \mathrm{dpi}$ )

deposition pace, the above observation suggests the varying papilla composition as one of the factors responsible for the pathogen penetration mode, and, hence, the plant resistance.

Involvement of host plant actin filaments in directing the defense response (papilla deposition) to A. brassicicola infection was studied afterwards. Phalloidin labeled with rhodamine effectively stained the actin filaments of both, the plant cells and A. brassicicola hyphae. From the seven tested protocols of actin staining, we only succeeded with one method (Olyslaegers and Verbelen 1998) with slight modifications. Further attempts at modifications of the staining procedure, such as exchange of buffering or chelating agents, failed to improve the stain. Taken together, this suggests that effective staining of actin networks requires extensive experimentation, depending on the analyzed species/pathosystem.

Based on our observations, pathogen inoculation resulted in rapid reorganization of the subcellular actin filaments networks, in terms of localization and densities. The inoculated plants showed strands of filaments running across the cells without particular order, but this changed drastically already at $2 \mathrm{dpi}$, and was confirmed at $4 \mathrm{dpi}$. The developing papilla served as focal point for actin filaments network, enclosing the papilla in a cocoon (Fig. 4). Although we failed to reliably calculate the high densities of the filaments in plants differing in response to A. brassicicola, our observations confirm the involvement of actin filaments in plant response to pathogen attack.

Taken together, our microscopic studies helped visualize the A. brassicicola infection process in plants differing in response to this pathogen. Based on the microscopic data, we posited that $A$. brassicicola assumes an infection mode depending on the plant resistance level. Novel data on lack of time or size (quantitative) differences between host papilla deposition in response to pathogen infection suggests qualitative differences in papilla composition in the moderately resistant vs. susceptible plants. Dramatic reorganization of plant cell actin filaments documents their participation in driving the defense responses irrespective of the cultigen resistance status.

Biochemical analyses of the A. brassicicola infection process

Most of the 10 analyzed biochemical parameters (three ROS species, two defensive substances, and five red-ox enzymic activities) showed significant interaction between cultigen and time after infection with A. brassicicola $(P<0.05$; Fig. 5). The sole exceptions were SOD and PGA, which lacked significant changes for neither of the factors nor their interaction.

The dynamics of ROS production in response to A. brassicicola inoculation was complex. The $\mathrm{O}_{2}{ }^{-}$ showed decreasing trend for the (moderately) resistant cultigens and no major changes for the others. The $\mathrm{H}_{2} \mathrm{O}_{2}$ showed generally higher levels in the (moderately) resistant forms and a decreasing trend throughout. The $\mathrm{OH}^{*}$ showed a generally decreasing trend in time, with PGH05I building-up its amounts up to $2 \mathrm{dpi}$.

The highest levels of lignins were recorded for C. sativa, but all cultigens showed their accumulation during infection. Free phenols showed no major differences throughout, although a noticeable peak manifested for PGH05I at $1 \mathrm{dpi}$.

Among the tested red-ox enzymes, PPO showed clear increasing trend with the infection progress. The highest levels of POX activation were recorded for the resistance standard, C. sativa. Measurements of CAT showed its activation with time after infection, again with $C$. sativa showing the highest activation when compared with baseline (0 dpi). 


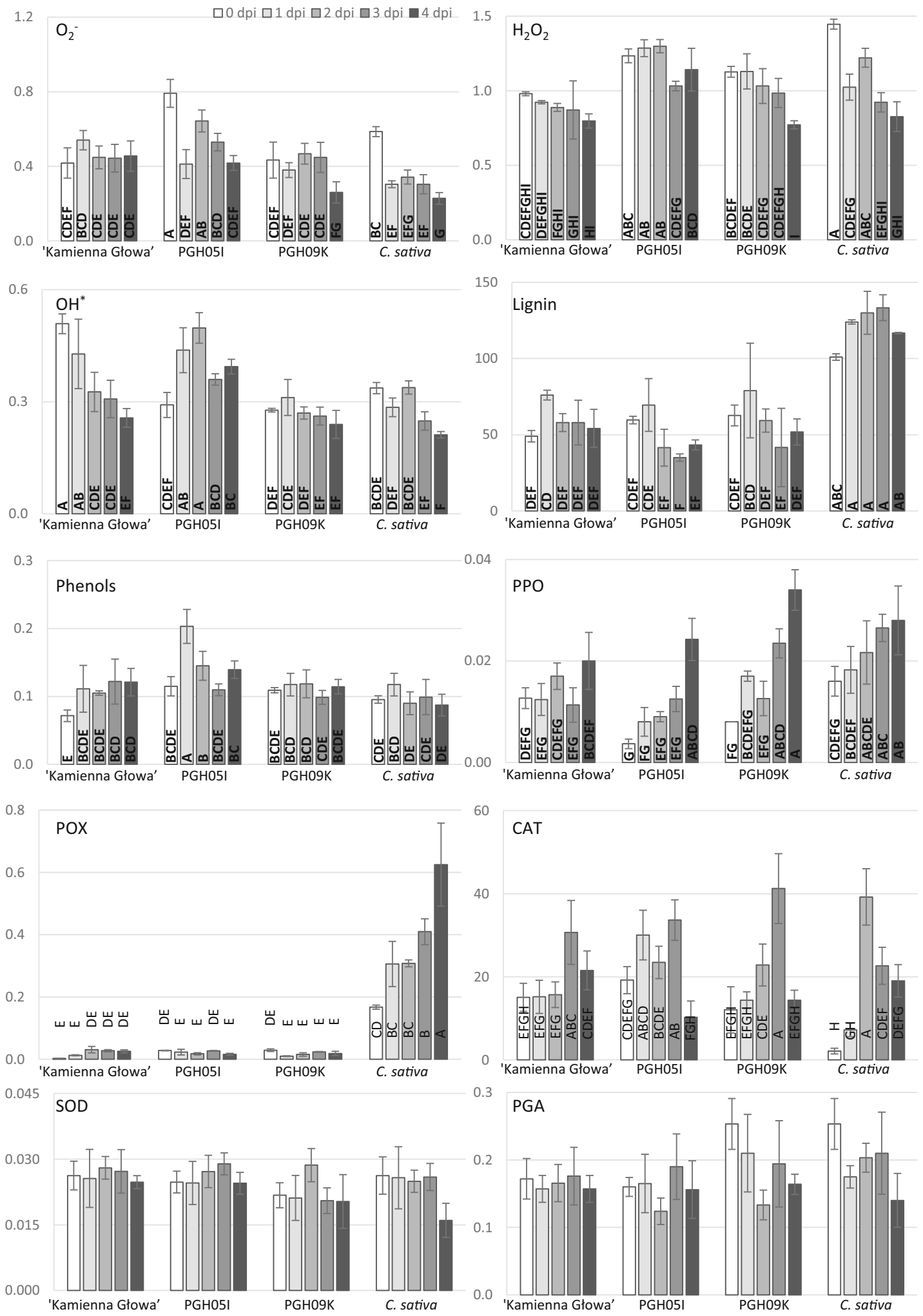


Fig. 5 Biochemical analyses of the Alternaria brassicicolaBrassicaceae pathosystem. Chosen four cultigens (45-day old seedlings) were inoculated and kept under the optimized bioassay coditions. Samples were taken daily from two plants per cultigen, from 0 to $4 \mathrm{dpi}$. The susceptible control 'Kamienna Głowa' started manifesting typical Alternaria dark spot symptoms at 3 dpi. Processed samples were used for analyses of dynamics of three ROS species, two defense substances, and five red-ox enzymic activities, with at least three technical reps per sample. Bars represent means with standard deviation. Datasets for each parameter were analyzed with two-way ANOVA $(\alpha=0.05)$, with posthoc Tukey's honest significant difference whenever significant $(P<0.05)$ interaction between cultigen and stage $($ dpi) were recorded. Data points with same letters do not differ significantly. The following parameters were analyzed (with respective standards, or absorbance vs. blanks): build-up of $\mathrm{O}_{2}^{-}\left(\mathrm{A}_{530}\right)$; build-up of $\mathrm{H}_{2} \mathrm{O}_{2}\left(\mathrm{H}_{2} \mathrm{O}_{2}\right.$ as standard; $\left.\mathrm{A}_{390}\right)$; build-up of $\mathrm{HO}^{*}\left(\mathrm{~A}_{560}\right)$; production of free phenols (gallic acid; $\mathrm{A}_{725}$ ); deposition of lignins (technical lignin; $\mathrm{A}_{280}$ ); dynamics of PPO (polyphenol oxidase; $\Delta \mathrm{A}_{420} / \mathrm{min} / \mathrm{mg}$ protein); dynamics of POX (guaiacol peroxidase; $\mu \mathrm{g}$ of metabolized guaiacol $/ \mathrm{min} / \mathrm{mg}$ protein; $\mathrm{A}_{460}$ ); dynamics of CAT (catalase; rates of dichromate acetate reduction $/ \mathrm{min} / \mathrm{mg}$ protein; $\mathrm{A}_{570}$ ); dynamics of SOD (superoxide dismutase; rates of epinephrine turnover $/ \mathrm{min} / \mathrm{mg}$ protein; $\mathrm{A}_{480}$ ); dynamics of PGA (polygalacturonase; rates of polygalacturonic acid digest $/ \mathrm{min} / \mathrm{mg}$ protein; $\mathrm{A}_{535}$ )

\section{Discussion}

Reliable methods for accurate evaluation of germplasm for pathogen resistance are an important issue for breeding programs. Disease resistance in a breeding program is best tested in the field, under natural pathogen infection. In contrast to this method, growth chamber tests can often be fast, efficient, and high-throughput. Therefore, we attempted optimization of the seedlings and detached leaf assays under controlled conditions for the brassicas - A. brassicicola pathosystem, varying the inoculum concentration, age of leaf, leaf position, and incubation temperature. We later assessed the reliability of these two methods, by comparing their results with data from the field assays.

Our data indicate an increased disease severity with an increase of inoculum concentration above the threshold of $10^{3}$ conidia $\times \mathrm{ml}^{-1}$ (with the exception of the resistant $S$. alba). Significantly higher disease intensity was recorded for the highest concentration of conidia $\left(10^{5} \times \mathrm{ml}^{-1}\right)$, compared with the two lowest inoculum loads used. Similar results were obtained for the effects of inoculum concentrations on $B$. rapa tested with A. brassicicola (Doullah et al. 2006) and B. napus tested with A. brassicae (Hong and Fitt 1995; Meena et al.
2016). Additionally, King (1994) noticed no significant differences in disease intensity for $B$. oleracea var. capitata and B. napus inoculated with $2.3 \times 10^{4}, 3.7 \times$ $10^{5}$, and $5 \times 10^{4}$ conidia $\mathrm{ml}^{-1}$ of $A$. brassicicola. Inoculum concentrations comparable with those used in our study $\left(10^{5}\right.$ conidia $\left.\mathrm{x} \mathrm{ml}^{-1}\right)$ or higher were successfully employed for evaluation of cultigens with various level of Alternaria spp. resistance (Gupta et al. 2013; Köhl et al. 2010; Mazumder et al. 2013; Scholze and Ding 2005; Tohyama \& Tsuda 1995).

Incubation temperature was important in our study for evoking the disease symptoms regardless of the plant material tested, particularly in the detached leaf assays. Optimized assay temperature of $25{ }^{\circ} \mathrm{C}$ resulting in the highest disease severity irrespective of the apparent cultigen's susceptibility, is in agreement with other studies of this pathosystem, or of the related A. brassiceae (Doullah et al. 2006; Gupta et al. 2013; Hong and Fitt 1995; Kennedy and Graham 1995; Mazumder et al. 2013; Rashid et al. 2011; Sharma et al. 2002; Su'udi et al. 2011; Zală et al. 2014). As our studies lacked major DSI differences between 22 and $25^{\circ} \mathrm{C}$, either temperature may be used for evaluating the germplasm resistance.

Using the detached leaf method, we observed that disease intensity scores were correlated with the leaf age, irrespective of the cultigen apparent resistance/susceptibility. Our data are in agreement with other previous reports, where the older leaves of Brassicaceae plants are more susceptible to infection by A. brassicicola than the younger leaves. Such "ageconditioned susceptibility" (Domsch 1957) was recorded in nearly all Alternaria-host pathosystems, including the oleiferous Brassicaceae crops, and their main pathogens - A. brassicae and A. brassicicola (Allen et al. 1983; Deep and Sharma 2012; Doullah et al. 2006; Hong and Fitt 1995; Rotem 1998; Saharan and Mehta 2002). Despite this observation being generally agreed on, differences exist in how the specific leaf ages influence disease severity. For instance, Deep and Sharma (2012) reported that the younger plants of a susceptible cauliflower at 15- and 30-day old plants did not show any leaf spot symptoms of $A$. brassicicola, in contrast to the 45- and 60-day old plants being very susceptible. In our studies, the intensity of symptoms gradually increased from the 35-day old plants, as they got older. Such differences in disease symptoms development might result from the inoculation techniques used, or, more likely, from the differences in pathogen 
aggressiveness or the genetic resistance of the plant materials. The environment may also play an important role in such investigations, especially since our tests were conducted under controlled conditions in the growth chambers, whereas the experiments of Deep and Sharma (2012) employed greenhouse conditions. It is generally accepted that even small changes in the environmental factors of a bio-assay may be critical for identification and categorization of susceptible or resistant genotypes (Kozik and Sobiczewski 2000).

It may be possible, as suggested by others (Horsfall and Dimond 1957), that susceptibility to necrotrophic pathogens, such as Alternaria spp., may result from the low sugar levels in older plants. The relationship between plant or leaf age and disease development has also been attributed to the amount of epicuticular wax on the leaf surface, as the plant aged (Conn and Tewari 1989). In our previous studies, the intensity of disease symptoms on the 1 st and 2 nd leaves of cauliflower and white cabbage plants infected by A. brassicicola did not depend on wax presence. But, removing the epicuticular wax resulted in a compartively higher disease intensity when testing the $3 \mathrm{rd}$ and younger leaves (Nowakowska, data not published).

The parameters optimized in our study were then used to enhance the stringency of both evaluation methods to compare the assay efficiencies of the selection process over a broad collection of cultigens. The main effect of the genotype of given cultigen on disease severity was stronger than the differences between the two inoculation methods. Therefore, either the detached leaf or seedlings test could be used as reliable tools to evaluate the A. brassicicola resistance among the Brassicaceae germplasm. These observations are in agreement with those of Doullah et al. (2006), who found a strong positive correlation between the detached leaf test and the seedling test using 56 cultivars of $B$. rapa. They also recommended the detached leaf method for primary screening and selection within the $B$. rapa accessions resistant against $A$. brassicicola, before final tests under natural field infection. The advantage of the detached leaf method over the seedlings test is a possibility for resistance evaluation in large populations within the germplasm collection. The same conclusions might be drawn from our results on disease assessment of Brassicaceae, in particular B. oleracea. Other authors have also found the detached leaf method to be simple, easy, and fast for evaluation of Alternaria spp. resistance in cabbage and cauliflower (Sharma et al. 2004). Similar outcome was presented for related pathosystems, where the detached leaf inoculation was the most efficient and reliable technique of four studied methods for screening of A. brassicae resistance in rape seed and mustard (Vishvanath \& Kolte 1999).

The unexpected outcome of this study was the differences between the evaluations using controlled conditions tests and field assessments of our cultigens. For cultigens showing less intense disease symptoms in the field than in the tests under the controlled conditions, the differences may have arisen from the particularly stringent conditions employed for the bio-assays. On the other hand, the cultigen PGH05I performed better under artificial inoculation, manifested by the marginally higher DSI under natural epidemiological conditions. This might indicate the presence of other stress factors: Local differences in growing conditions or climate (Hong and Fitt 1995; Scholze 2002; Shrestha et al. 2005), suboptimal developmental stage upon pathogen incidence, or presence of other pathogens under natural epidemiological conditions, in particular the opportunistic ones such as A. alternata (Kubota et al. 2006; Michereff et al. 2012; Tohyama \& Tsuda 1995). Under natural infection in the field, the conidia concentration may be low, and plants may escape infection (Sharma et al. 2002), hence the need to repeatedly test the resistance of the established breeding materials in the field to prevent escapes. Further, the length of vegetative period of the tested cultigens of cabbage also plays an important role in the susceptibility to A. brassicicola in the field. This hypothesis was confirmed by our results for the early cultigens such as 'Sława z Enkhuizen', 'Kilagreg $\mathrm{F}_{1}$ ', and PGH24K, showing lower infestation symptoms in the field, whereas the late cultigens such as PGH09K or PGH30K were more susceptible. Comparatively, higher resistance of the interspecific hybrid PGH05I was recorded at 120 days of vegetation, and therefore was independent of the plant age. The Chinese cabbage cultigens ('Bilko $\mathrm{F}_{1}$ ', PGH33P, PGH12P) and two lines of swede (PGH10P, PGH11P) were susceptible in the field irrespective of their short vegetation period. Due to these and other factors influencing the severity, field assays with or without inoculation may be inappropriate for evaluation of germplasm at the early stage of resistance breeding (Sharma et al. 2002). It is worth noting, however, that the disagreements of disease intensity observed here, mostly do not influence the apparent cultigen resistance, i.e., cultigens classified as "moderately resistant" in the bio-assays do not change 
their status to "susceptible" under the field trials. Rather, most changes in this respect occurred for the group of cultigens classified as "susceptible" in the bio-assays but "moderately resistant" in the field. This, however, would have only a minor impact on the outcome of the selection process, as the susceptible cultigens would have been discarded in the stringent preliminary laboratory screens, at the early stages of selection. Yet, in case of limited germplasm pool, cauliflower being the case in this study, such moderate resistance recorded in the field may prove the only resort for the subsequent breeding.

We decided to use a mixture of pathogen isolates for screening of our collection of Brassicaceae cultigens, by selecting the isolates highest in aggressiveness as per the preliminary assays. Other scholars of this pathosystem have used isolates with contrasting pathogenicity towards the host plants (Cho et al. 2006; Pochon et al. 2013; Su'udi et al. 2011). Alternatively, and similar to our approach, plants with varying reactions to the pathogen were used for experimentation (Doullah et al. 2006; Mazumder et al. 2013; Meena et al. 2011; Sharma et al. 2002). Testing a modest local collection of A. brassicicola and A. brassicae isolates from infected cauliflower plants indicated differences among three cultivars in a detached-leaf assay (Deep and Sharma 2012). Common difficulties currently experienced in studying this pathosystem deal in particular with lack of pathogen/testing standardization described above and lack of pathogen resistance sources among the cultivated cultigens (Kumar et al. 2014; Nowicki et al. 2012b; Sharma et al. 2002). Moreover, using a mixture of isolates in the laboratory bio-assay would likely mimic the field condition, and help conclude on the field data.

Several attempts have been made to discover the sources of high level resistance against A. brassicicola or A. brassicae, but until now no such materials have been identified among the cultivated species of the Brassica genus (reviewed in Kumar et al. 2014; Nowicki et al. 2012b). High levels of resistance against these pathogens have been reported in the wild relatives of Brassica inside and outside the tribe Brassicaceae (reviewed by Kumar et al. 2014). Our study on assessment of $A$. brassicicola resistance among 38 cultigens including mainly $B$. oleracea (18 head cabbage, six cauliflowers), three Chinese cabbages $B$. rapa, but also four interspecific crosses and five B. napus accessions, revealed lack of high $A$. brassicicola resistance, when compared with the most resistant plants of $C$. sativa and $S$. alba. All the remaining cultigens (head cabbage, cauliflower, Chinese cabbage, rape) displayed various levels of susceptibility. This is in agreement with related studies (Cherukuri et al. 2011), also pointing out lack of true source of resistance against $A$. brassicae among the B. oleracea, B. campestris, B. nigra, B. juncea, $B$. napus, and $B$. carinata accessions. Interestingly, an assessment of $A$. brassiceae resistance among 38 cultigens (Sharma et al. 2002) indicated that vegetable brassicas (cauliflower, cabbage, and broccoli) were comparatively less susceptible than the cultivated oilseed brassicas. Our bio-assay data prove the genetic control over moderate $A$. brassicicola resistance in two inter-specific hybrid cultigens (PGH05I, PGH25I). Therefore, these might be promising sources of A. brassicicola resistance in the future brassicas breeding efforts.

Our microscopic observations of the A. brassicicolahost interaction resulted in visualization of the pathogen cycle, including: Germinating conidia, aerial hyphae formation and growth, infection structures (appressoria and haustoria), and development of secondary hyphae. Simultaneously, we observed the defense responses in host plant leaves: A drastic reorganization of actin networks, deposition of papillae, cell death upon colonization, and limitation of pathogen spread by callose deposition around the infected cell(s). Some authors (Pochon et al. 2013; Sharma et al. 2014) reported on A. brassicicola infection routes (i.e., leaf penetration modes) depending on a given isolate aggressiveness but agreed on both direct (epidermal) and stomatal penetration possible for the Alternaria spp. in several pathosystems. In particular, Sharma et al. (2014) claimed an aberrant behavior of the least aggressive isolate, only attempting the direct penetration. Also, McRoberts and Lennard (1996) diligently tested the host and non-host reactions of susceptible plant materials on an array of Alternaria species; it could be their use of susceptible lines that resulted in comparatively low proportion of stomatal attempted infections. In contrast, we studied the infection mode in relation to host plant's resistance in cultigens showing different reactions to inoculation with $A$. brassicicola. The highly susceptible cultigens were readily infected by direct epidermal penetration, whereas the host defenses present in the moderately resistant cultigen PGH05I and the resistance standard $S$. alba necessitated infection by the stomata, despite their comparatively higher density in those cultigens. This observation needs to be confirmed on a larger array of cultigens, with diverse 
A. brassicicola responses. Rapid subcellular changes upon the perceived pathogen attack were further underscored by strong microscopic evidence of the actin networks engaging in defense responses, tightly surrounding the developing papilla - irrespective of the host plant resistance. It is in agreement with McRoberts and Lennard (1996), who reported such rapid primary resistance response in both host and non-host systems as well, but also claimed callose deposition per se relatively unimportant to the outcome of the resistance response. Thus, also in the light of our findings, further research on the papilla composition in plants of contrasting A. brassicicola response might shed more light on the background of molecular mechanisms of resistance in either cultigen. Investigations of plant hormones interplay (jasmonic acid, abscisic acid, and salicylic acid) (Mazumder et al. 2013; Su'udi et al. 2011) and their influence on host plant susceptibility/resistance is of particular import for comprehension of the subcellular defense mechanisms in the pathosystem studied here. Indeed, a link was suggested between the biochemical response of cabbages to A. brassicicola infection, by the action of salicylic acid (Wang et al. 2009).

Important biochemical mechanisms of $A$. brassicicola resistance involved all three common defense branches: ROS signaling, accumulation of defensive substances, and activation of red-ox enzymes. Our analyses suggested an interplay of $\mathrm{H}_{2} \mathrm{O}_{2}$ levels with catalase activation, as the infection progressed, highlighting this ROS as particularly important in the analyzed pathosystem. This was further underlined by the increasing activities of peroxidase in the resistant $C$. sativa plants. Indeed, previous research indicated this ROS as important signaling molecule in the A. brassicicola infection (Su'udi et al. 2011). Similarly, several of the biochemical parameters studied here were previously analyzed in this pathosystem, yet with different two cabbage cultigens of contrasting pathogen responses (Wang et al. 2008; Pogány et al. 2009).

Another example of such interplay was between the free phenols levels and the polyphenol oxidase dynamics: Despite rather stable levels of the free phenolics detected, the enzyme activity increased as the infection progressed. Together with the dynamics of lignin deposition, these observations further indirectly supported our claim of qualitative (composition and contents) differences in the papilla determining the plant response - successful defense or successful infection. Papilla reinforcement was suggested as a defense mechanism against $A$. brassicicola (Glazebrook 2005), as a mode of chemical defense with antimicrobial compounds or proteins; or physical with callose, lignins, and phenolics.

\section{Conclusions}

The genetic control of the Brassicaceae cultigens resistance against $A$. brassicicola played a crucial role in determining the pathosystem interaction outcome, irrespective of which of the two phytotron testing methods was employed. From the bio-assay variables undergoing optimization, the developmental stage of the materials tested had the largest influence on the disease severity, in agreement with the accepted "age-conditioned susceptibility" for Alternaria blight. Inoculum concentration, followed by incubation temperature, also influenced the disease severity. All parameters affected the reaction of the plant to the pathogen, irrespectively of their resistance status. Reactions to the pathogen lacked major differences under the two phytotron methods used, but several cultigens performed comparatively better in the field, suggesting that we applied particularly stringent conditions for either detached leaf or seedlings tests. Two interspecific hybrids with promising levels of A. brassicicola resistance were identified from among the pool of 38 cultigens included in this study, with a potential for further resistance breeding and phyto-pathological studies. Microscopic visualization of the infection process in cultigens differing in their susceptibility levels helped formulate a novel hypothesis on differences in pathogen infection mode being related to the host plant resistance. Also, papilla composition is likely an important factor in the resistance of the host plant, with actin networks participating in generating the defense responses. Our bio-assays protocols, biochemical, and microscopic data contribute a material advancement in the economically important brassicasA. brassicicola pathosystem.

Acknowledgements Authors recognize the excellent technical contribution of Ms. Marzena Czajka, Mrs. Krystyna Szewczyk, Mrs. Małgorzata Pakuła, and Mr. Ireneusz Werkowski into this study. Dr. Michael Havey (University of Wisconsin-Madison, USA) and Dr. Todd C. Wehner (North Carolina State University, USA) are gratefully acknowledged for critical reading of this manuscript. Dr. Dorothy M. Tappenden (Michigan State 
University and Lansing Community College, MI, USA) provided great editorial help with this manuscript. We are grateful to Prof. Dr. hab.Hanna Kwaśna (Poznań University of Life Sciences) for help with pathogen identification. Pathogen banks (Geves - Snes National Seed Testing Station, France; CBS-KNAW Collections, the Netherlands) are gratefully acknowledged for the strains of A. brassiceae and A. brassicicola. The research reported herewith was financed by the Polish Ministry of Agriculture and Rural Development research grant HORhn 8421/1/2012.

Funding This study was funded by the Polish Ministry of Agriculture and Rural Development research grant HORhn 8421/1/ 2012, granted to the Research Institute of Horticulture, Skierniewice, Poland.

\section{Compliance with ethical standards}

Conflict of interest Author Marzena Nowakowska declares that she has no conflict of interest.

Author Małgorzata Wrzesińska declares that she has no conflict of interest.

Author Piotr Kamiński declares that he has no conflict of interest. Author Wojciech Szczechura declares that he has no conflict of interest.

Author Małgorzata Lichocka declares that she has no conflict of interest.

Author Michał Tartanus declares that he has no conflict of interest. Author Elżbieta U. Kozik declares that she has no conflict of interest.

Author Marcin Nowicki declares that he has no conflict of interest.

Ethical approval This article does not contain any studies with human participants or animals performed by any of the authors.

Open Access This article is distributed under the terms of the Creative Commons Attribution 4.0 International License (http:// creativecommons.org/licenses/by/4.0/), which permits unrestricted use, distribution, and reproduction in any medium, provided you give appropriate credit to the original author(s) and the source, provide a link to the Creative Commons license, and indicate if changes were made.

\section{References}

Abràmoff, M. D., Magalhães, P. J., \& Ram, S. J. (2004). Image processing with ImageJ. Biophotonics International, 11, 3642.

Allen, S., Brown, J., \& Kochman, J. (1983). Effects of leaf age, host growth stage, leaf injury, and pollen on the infection of sunflower by Alternaria helianthi. Phytopathology, 73(6), 896-898.

Bock, C. H., Thrall, P. H., Brubaker, C. L., \& Burdon, J. J. (2002). Detection of genetic variation in Alternaria brassicicola using AFLP fingerprinting. Mycological Research, 106, 428-434.

Brazauskienè, I., Petraitienè, E., Brazauskas, G., \& Semaškienè, R. (2011). Medium-term trends in dark leaf and pod spot epidemics in Brassica napus and Brassica rapa in Lithuania. Journal of Plant Diseases and Protection, 197-207.

Campbell, M. M., \& Ellis, B. E. (1992). Fungal elicitor-mediated responses in pine cell cultures: Cell wall-bound phenolics. Phytochemistry, 31, 737-742.

Chang, X., \& Nick, P. (2012). Defence signalling triggered by Flg22 and harpin is integrated into a different stilbene output in Vitis cells. PLoS One, 7, e40446-e40446.

Cherukuri, S. C., Plaha, P., \& Sharma, R. (2011). Evaluation of some cultivated brassicas and their related alien species for disease resistance. Cruciferae Newsletter, 30, 18-22.

Cho, Y., Davis, J. W., Kim, K.-H., Wang, J., Sun, Q.-H., Cramer Jr., R. A., \& Lawrence, C. B. (2006). A high throughput targeted gene disruption method for Alternaria brassicicola functional genomics using linear minimal element (LME) constructs. Molecular PlantMicrobe Interactions, 19, 7-15.

Conn, K., \& Tewari, J. (1989). Interactions of Alternaria brassicae conidia with leaf epicuticular wax of canola. Mycological Research, 93, 240-242.

Conn, K., Tewari, J., \& Awasthi, R. (1990). A disease assessment key for Alternaria black spot in rapeseed and mustard. Disease des plantes Survey'au Canada, 70, 19.

Cvikrova, M., Binarova, P., Eder, J., \& Nedělník, J. (1992). Accumulation of phenolic acids in filtrate-treated alfalfa cell cultures derived from genotypes with different susceptibility to fusarium oxysporum. Journal of Plant Physiology, 140, 21-27.

Deep, S., \& Sharma, P. (2012). Host age as predisposing factor for incidence of black leaf spot of cauliflower caused by Alternaria brassicae and Alternaria brassicicola. Indian Phytopathology, 65, 71-75.

Domsch, K. v (1957). Die Raps-und Kohlschotenschwärze. Zeitschrift für Pflanzenkrankheiten (Pflanzenpathologie) und Pflanzenschutz:65-79.

Doullah, M., Meah, M., \& Okazaki, K. (2006). Development of an effective screening method for partial resistance to Alternaria brassicicola (dark leaf spot) in Brassica rapa. European Journal of Plant Pathology, 116, 33-43.

Glazebrook, J. (2005). Contrasting mechanisms of defense against biotrophic and necrotrophic pathogens. Annual Review of Phytopathology, 43, 205-227.

Gupta, P., Ravi, I., \& Sharma, V. (2013). Induction of $\beta-1,3-$ glucanase and chitinase activity in the defense response of Eruca sativa plants against the fungal pathogen Alternaria brassicicola. Journal of Plant Interactions, 8, 155-161.

Habu, J. B., \& Ibeh, B. O. (2015). In vitro antioxidant capacity and free radical scavenging evaluation of active metabolite constituents of Newbouldia laevis ethanolic leaf extract. Biological Research, 48, 16.

Hansen, L. N., \& Earle, E. D. (1997). Somatic hybrids between Brassica oleracea L. and Sinapis alba L. with resistance to Alternaria brassicae (Berk.) Sacc. Theoretical and Applied Genetics, 94(8), 1078-1085.

Hong, C., \& Fitt, B. D. (1995). Effects of inoculum concentration, leaf age and wetness period on the development of dark leaf 
and pod spot (Alternaria brassicae) on oilseed rape (Brassica napus). Annals of Applied Biology, 127, 283-295.

Horsfall, J. G., and Dimond, A. 1957. Interactions of tissue sugar, growth substances, and disease susceptibility. Zeitschrift für Pflanzenkrankheiten (Pflanzenpathologie) und Pflanzenschutz:415-421.

Humpherson-Jones, F., \& Phelps, K. (1989). Climatic factors influencing spore production in Alternaria brassicae and Alternaria brassicicola. Annals of Applied Biology, 114, 449-458.

Kasprzyk, I., Sulborska, A., Nowak, M., Szymańska, A., Kaczmarek, J., Haratym, W., Weryszko-Chmielewska, E., \& Jędryczka, M. (2013). Fluctuation range of the concentration of airborne Alternaria conidiospores sampled at different geographical locations in Poland (2010-2011). Acta Agrobotanica, 66, 65-76.

Kennedy, R., and Graham, A. 1995. Infection of oil-seed rape by Alternaria brassicae under varying conditions of temperature and wetness. Proceedings of the 9th International Rapeseed Congress, Cambridge, UK. p 603.

King, S. R. 1994. Screening, selection, and genetics of resistance to Alternaria diseases in Brassica oleracea: Cornell University, August.

Kobayashi, Y., Yamada, M., Kobayashi, I., \& Kunoh, H. (1997). Actin microfilaments are required for the expression of nonhost resistance in higher plants. Plant and Cell Physiology, 38, 725-733.

Köhl, J., Van Tongeren, C., Groenenboom-de Haas, B., Van Hoof, R., Driessen, R., \& Van Der Heijden, L. (2010). Epidemiology of dark leaf spot caused by Alternaria brassicicola and A. brassicae in organic seed production of cauliflower. Plant Pathology, 59, 358-367.

Korgan, S., Wolski, E. A., Cicore, P., Suarez, P., Capezio, S., Huarte, M. A., \& Andreu, A. B. (2011). Solanum tarijense reaction to Phytophthora infestans and the role of plant defence molecules. Plant Breeding, 130, 231-236.

Kozik, E. U., \& Sobiczewski, P. (2000). Response of tomato genotypes to bacterial speck (Pseudomonas syringae pv. tomato). Acta Physiologiae Plantarum, 22(3), 243-246.

Kubota, M., Abiko, K., Yanagisawa, Y., \& Nishi, K. (2006). Frequency of Alternaria brassicicola in commercial cabbage seeds in Japan. Journal of General Plant Pathology, 72, 197204.

Kumar, D., Maurya, N., Bharati, Y. K., Kumar, A., Kumar, K., Srivastava, K., Chand, G., Kushwaha, C., Singh, S. K., \& Mishra, R. K. (2014). Alternaria blight of oilseed brassicas: A comprehensive review. African Journal of Microbiology Research, 8, 2816-2829.

Langenberg, W. (1978). Relative speed of fixation of glutaraldehyde and osmic acid in plant cells measured by grana appearance in chloroplasts. Protoplasma, 94, 167-173.

Loreto, F., \& Velikova, V. (2001). Isoprene produced by leaves protects the photosynthetic apparatus against ozone damage, quenches ozone products, and reduces lipid peroxidation of cellular membranes. Plant Physiology, 127, 1781-1787.

Loreto, F., Mannozzi, M., Maris, C., Nascetti, P., Ferranti, F., \& Pasqualini, S. (2001). Ozone quenching properties of isoprene and its antioxidant role in leaves. Plant Physiology, 126, 993-1000.

Maisch, J., \& Nick, P. (2007). Actin is involved in auxindependent patterning. Plant Physiology, 143, 1695-1704.
Mazumder, M., Das, S., Saha, U., Chatterjee, M., Bannerjee, K., \& Basu, D. (2013). Salicylic acid-mediated establishment of the compatibility between Alternaria brassicicola and Brassica juncea is mitigated by abscisic acid in Sinapis alba. Plant Physiology and Biochemistry, 70, 43-51.

McRoberts, N., \& Lennard, J. H. (1996). Pathogen behaviour and plant cell reactions in interactions between Alternaria species and leaves of host and nonhost plants. Plant Pathology, 45(4), 742-752.

Meena, P., Meena, R., Chattopadhyay, C., \& Kumar, A. (2004). Identification of critical stage for disease development and biocontrol of Alternaria blight of Indian mustard (Brassica juncea). Journal of Phytopathology, 152, 204-209.

Meena, P. D., Chattopadhyay, C., Meena, S. S., \& Kumar, A. (2011). Area under disease progress curve and apparent infection rate of Alternaria blight disease of Indian mustard (Brassica juncea) at different plant age. Archives of Phytopathology and Plant Protection, 44, 684-693.

Meena, P. D., Jambhulkar, S. J., Gupta, R., Meena, H. S., \& Singh, D. (2016). Rapid screening technique for Alternaria blight resistance in Indian mustard (Brassica juncea L.) using cotyledonary leaf method. Journal of Plant Pathology, 98(3), 463-469.

Michereff, S. J., Noronha, M. A., Xavier Filha, M. S., Câmara, M. P., \& Reis, A. (2012). Survey and prevalence of species causing Alternaria leaf spots on Brassica species in Pernambuco. Horticultura Brasileira, 30, 345-348.

Miklis, M., Consonni, C., Bhat, R. A., Lipka, V., Schulze-Lefert, P., \& Panstruga, R. (2007). Barley MLO modulates actindependent and actin-independent antifungal defense pathways at the cell periphery. Plant Physiology, 144, 11321143.

Moukette, B. M., Pieme, C. A., Njimou, J. R., Biapa, C. P. N., Marco, B., \& Ngogang, J. Y. (2015). In vitro antioxidant properties, free radicals scavenging activities of extracts and polyphenol composition of a non-timber forest product used as spice: Monodora myristica. Biological Research, 48, 15.

Nowicki, M., Lichocka, M., Nowakowska, M., Kłosińska, U., \& Kozik, E. U. (2012a). A simple dual stain for detailed investigations of plant-fungal pathogen interactions. Vegetable Crops Research Bulletin, 77, 61-74.

Nowicki, M., Nowakowska, M., Niezgoda, A., \& Kozik, E. (2012b). Alternaria black spot of crucifers: Symptoms, importance of disease, and perspectives of resistance breeding. Vegetable Crops Research Bulletin, 76, 5-19.

Nowicki, M., Kłosińska, U., Szczechura, W., Markiewicz, M., Sowik, I., Michalczuk, L., and Kozik, E. U. 2016. Cellular and biochemical mechanisms of cucumber resistance against Pseudoperonospora cubensis. In: Cucurbitaceae 2016, XIth Eucarpia Meeting on Cucurbit Genetics \& Breeding, July 24-28, 2016, Warsaw, Poland (pp. 128-131). Cucurbitaceae 2016 Organizing Committee.

Olyslaegers, G., \& Verbelen, J. (1998). Improved staining of Factin and co-localization of mitochondria in plant cells. Journal of Microscopy, 192, 73-77.

Opalski, K. S., Schultheiss, H., Kogel, K.-H., \& Hückelhoven, R. (2005). The receptor-like MLO protein and the RAC/ROP family G-protein RACB modulate actin reorganization in barley attacked by the biotrophic powdery mildew fungus Blumeria graminis f. Sp. hordei. The Plant Journal, 41, 291303. 
Pochon, S., Simoneau, P., Pigné, S., Balidas, S., BatailléSimoneau, N., Campion, C., Jaspard, E., Calmes, B., Hamon, B., \& Berruyer, R. (2013). Dehydrin-like proteins in the necrotrophic fungus Alternaria brassicicola have a role in plant pathogenesis and stress response. PLoS One, 8, e75143.

Pogány, M., von Rad, U., Grün, S., Dongó, A., Pintye, A., Simoneau, P., Bahnweg, G., Kiss, L., Barna, B., \& Durner, J. (2009). Dual roles of reactive oxygen species and NADPH oxidase RBOHD in an Arabidopsis-Alternaria pathosystem. Plant Physiology, 151(3), 1459-1475.

Rashid, M., Hossain, I., \& Khalequzzaman, K. (2011). Effect of weather factors on inoculum density and leaf spot development in radish seed crop infected with Alternaria brassicae. Bulletin of the Institute of Tropical Agriculture, Kyushu University, 34, 43-47.

Rotem, J. (1998). The biotic and physiological components of pathogenesis. The Genus Alternaria; Biology, Epidemiology, and Pathogenicity, The American Phytopathological Society, St Paul, MN:95-118.

Saharan, G., and Mehta, N. 2002. Fungal diseases of rapeseedmustard. Diseases of field crops:193-228.

Scholze, P. (2002). In-vitro-germinability of conidia and differences in aggressivity in Alternaria brassicicola isolates on brassicaceous vegetables (Brassica oleracea L.). Pflanzenschutz Berichte, 60, 105-114.

Scholze, P., and Ding, Y. (2005). Manifestation of black spot disease (Alternaria brassicicola) in intact leaves and detached leaf segments of cabbage plants grown in nutrient solutions without $\mathrm{N}, \mathrm{P}, \mathrm{K}$ and $\mathrm{Ca} /$ Manifestierung der Schwarzfleckigkeit (Alternaria brassicicola) auf intakten Blättern und isolierten Blattsegmenten von Kohlpflanzen, die mit Nährlösungen ohne N, P, K und Ca ernährt wurden. Zeitschrift für Pflanzenkrankheiten und Pflanzenschutz/ Journal of Plant Diseases and Protection:562-572.

Sharma, G., Kumar, V. D., Haque, A., Bhat, S., Prakash, S., \& Chopra, V. (2002). Brassica coenospecies: A rich reservoir for genetic resistance to leaf spot caused by Alternaria brassicae. Euphytica, 125, 411-417.

Sharma, P., Sharma, S., \& Sindhu, M. (2004). A detached leaf technique for evaluation of resistance in cabbage and cauliflower against three major pathogens. Indian Phytopathology, 57, 315-318.

Sharma, P., Deep, S., Bhati, D. S., Sharma, M., \& Chowdappa, P. (2014). Penetration and infection processes of Alternaria brassicicola on cauliflower leaf and Alternaria brassicae on mustard leaf: A histopathological study. Plant Pathology Journal, 13, 100.

Sheehy, R. E., Kramer, M., \& Hiatt, W. R. (1988). Reduction of polygalacturonase activity in tomato fruit by antisense RNA. Proceedings of the National Academy of Sciences, 85, 88058809.

Shrestha, S. K., Munk, L., \& Mathur, S. B. (2005). Role of weather on Alternaria leaf blight disease and its effect on yield and yield components of mustard. Nepal Agricultural Research Journal, 6, 62-72.

Su'udi, M., Kim, M. G., Park, S.-R., Hwang, D.-J., Bae, S.-C., \& Ahn, I.-P. (2011). Arabidopsis cell death in compatible and incompatible interactions with Alternaria brassicicola. Molecules and Cells, 31, 593-601.

Vitha, S., Baluška, F., Braun, M., Šamaj, J., Volkmann, D., \& Barlow, P. W. (2000). Comparison of cryofixation and aldehyde fixation for plant actin immunocytochemistry: Aldehydes do not destroy F-actin. The Histochemical Journal, 32, 457-466.

Wang, L.-Y., Hou, X.-L., Liu, L., \& Chen, X.-F. (2008). Effects of Alternaria brassicicola (Berkeley) Saccardo infection on activities of protective enzymes and $\mathrm{H} 2 \mathrm{O} 2$ content in nonheading Chinese cabbage. Acta Horticulturae Sinica, 35(7), 1065-1068.

Wang, L.-Y., Hou, X.-L., \& Chen, X.-F. (2009). Study on mechanism of induced resistance to black spot disease by SA in non-heading Chinese cabbage. Journal of Nanjing Agricultural University, 32(4), 23-27.

Zală, C. R., Cristea, S., Gruia, L., and Manole, S. (2014). Research on the biology of the Alternaria brassicae fungus isolated from mustard. In: Mastorakis N, Mladenov V, Anisor N, Mijatovic I, Dumitrascu D, and Erol A, editors. 3rd International Conference on Energy and Environment Technologies and Equipment. Brasov, Romania. p 161-164. 